\title{
Limited Repair of Critical DNA Damage in Cells Exposed to Low Dose Radiation
}

\author{
Azhub Gaziev1,* and Gadzhi Shaikhaev ${ }^{2}$ \\ ${ }^{1}$ Institute of Theoretical and Experimental Biophysics, \\ Russian Academy of Sciences, Pushchino, \\ ${ }^{2}$ Vavilov Institute of General Genetics, \\ Russian Academy of Sciences, Moscow, \\ Russia
}

\section{Introduction}

Studies on the effects of low doses of ionizing radiation (IR) on living organisms in the last decade have received considerable development. There are numerous investigations that contribute to our knowledge of how post-radiation processes develop, and after small and low-intensity doses of IR in particular.

Nevertheless discussions about the quantitative threshold of radiation dose have been continued. A linear non-threshold (LNT) model has been accepted as a basic standard for radiation protection and risk estimates over many years. The LNT model postulates a linear dependence of biological effects on IR dose. Also, this model suggests that low-dose induced damage does not markedly contribute to the risk because a great deal of endogenous (spontaneous) lesions to the genome continuously arise and are repaired in the cell. However there is considerable experimental evidence that allows the suggestion that IR-induced DNA lesions increase linearly with dose, but the reaction of cells to these lesions and the efficiency of repair of most critical injuries may be nonlinear (Tubiana et al., 2006).

Low radiation doses may increase the risk of cancer development (NRC, 2006, Brenner et al., 2003) and, probably, of non-cancer pathologies (Hildebrandt, 2010).

Though the notion of "low doses" is not formally determined, this dose interval is defined in many reports as $\leq 100-200 \mathrm{mSv}$. In the BEIR VII report of the National Academy of Sciences of USA, the low dose is determined as a dose not exceeding $100 \mathrm{mSv}$ (NRC, 2006). Most likely, such doses (not more than $100 \mathrm{mSv}$ ) may be considered as "low doses". To the point, $100 \mathrm{mSv}$ exceeds nearly 100 times the average yearly natural background ( 1.0 mGy) of low linear energy transfer (LET).

This paper is a review of studies of cellular response to the critical DNA damage induced by ionizing radiation. Mechanisms are elucidated that limit the efficiency of repair of such lesions arising in cells irradiated with low doses of ionizing radiation. However, the analysis requires clarification of specific differences between the DNA damage induced by IR and endogenous lesions. 


\section{Endogenous and radiation-induced DNA damage}

Endogenous DNA lesions constantly arise in cells. So, according to Lindahl (1993), in the DNA of one cell during one day there may be around 50000 single-strand breaks (SSB), 10 000 apurinic/apyrimidinic sites (AP sites), 2000 oxidative lesions, 5000 alkylating lesions, 10 double-strand breaks (DSB) and 10 interstrand cross-linkings (ICL). These lesions to DNA result from the hydrolytic reactions, the action of reactive oxygen species (ROS) and other reactive metabolites (Lindahl, 1993; Bont, and van Larebeke, 2004). ROS induce modifications in DNA bases, SSB, AP sites, and DSB as a result of a close match of SSB (Bont, and van Larebeke, 2004).

ROS cause damage not only to DNA but also to lipids and other intracellular molecules. Therewith, the products of lipid: malondialdehyde (MDA), crotonaldehyde, acrolein, 4hydroxynonenal can interact with DNA to form injuries. In particular, MDA is able to form in DNA ICL (Marnett, 2002). Apart from ROS, the cells contain other reactive molecules that may damage DNA. The most significant of them is S-adenosylmethionine (SAM). This is a donor of the methyl group of the enzymatic DNA methylation, which plays a role in the regulation of gene expression. However, SAM can also exercise the non-enzymatic methylation of DNA to yield mutagenic base adducts, such as 7-methylguanine, 3methyladenine and $\mathrm{O}^{6}$-methylguanine in mammalian cells (Barnes and Lindahl, 2004). Other endogenous non-enzymatic methylating agents are betaine and choline.

Endogenous hydrolytic DNA lesions arise due to instability of the glycoside bond between the bases and deoxyribose. This connection is broken upon temperature increase, base alkylation or as a result of action of DNA-N- glycosylases. Break of the N-glycoside bond leads to arising of AP sites in DNA (Lindahl, 1993; Barnes and Lindahl, 2004). DNA bases are also subject to hydrolysis and deamination. These events more intensively occur in the single-stranded DNA than in double-stranded. Cytosine and its homologue 5methylcytosine are largely susceptible to deamination. Every day about 100-500 cytosines within DNA of one cell are subject to deamination and convert into uracils (Barnes and Lindahl, 2004).

Endogenous DNA lesions such as DSB and ICL, although arising in small proportion, approximately 10 per day on cell genome, are most critical for the fate of cells compared to a multiplicity of other injuries (Lieber, 2010; Dextraze et al., 2010). Endogenous DSB may arise in DNA not only as a result of ROS action, but also by programmed genome rearrangements such as $\mathrm{V}(\mathrm{D}) \mathrm{J}$ recombination (in lymphoid cells of the immune system) or due to meiotic recombination, shortening of telomeres, in the processes of transcription, replication, and as a result of random influence of DNA metabolic enzymes (Lieber, 2010).

Normally, the endogenous DNA lesions are not accumulated because in the cell there are constantly functioning repair mechanisms targeted at removing various types of damage. Most of these injuries are repaired by the mechanisms of base excision repair (BER). Adducts of non-enzymatic methylation may also be removed by BER enzymes, except for $\mathrm{O}^{6}$-methylguanine. The latter is removed from DNA by excision of the methyl group from guanine by $\mathrm{O}^{6}$-methylguanine-DNA methyltransferase (Barnes and Lindahl, 2004).

Thus, to maintain genome stability and long-term viability, normal cells possess a repair system for eliminating constantly arising endogenous lesions at maximum accuracy and efficiency.

This conclusion entails two questions. First: what is the difference between an endogenous DNA damage and a DNA damage induced by IR? Second: if in the cells significant amounts 
of endogenous DNA lesions are constantly repaired, then whether or not the additional damage induced by low doses of IR may "overload" the repair systems of the cell? Let us consider both of these versions.

IR induces multiple injuries to DNA of various chemical natures either as a result of direct ionization of DNA molecules, or indirectly through free radicals - the products of radiolysis of water and other intracellular compounds. In the cell there arise a variety of single DNA lesions: modified bases, SSB, AP sites, DNA-protein crosslinks, as well as complex injuries, such as DSB, ICL, replication fork destruction and the sites with long single-strand gaps (ssDNA) (Ward, 1988; Gaziev, 1999).

The main distinction of IR-induced DNA lesions from endogenous ones is their complex chemical nature and clustering of the former. Furthermore, the percentage of complex DNA lesions, critical for the fate of the cell, is much higher in the case of IR influence. As noted above, among endogenous DNA lesions arising in one cell per day, SSB and DSB are in the ratio 5000:1 (Lindahl, 1993; Barnes and Lindahl, 2004). Whereas for IR-induced lesions this ratio is: 20:1 (Ward, 1988).

The Biological efficiency of some amount of IR-induced DNA damage is much higher than that of the same amount of endogenous DNA damage, or that induced by chemical oxidants like $\mathrm{H}_{2} \mathrm{O}_{2}$ (Dextraze et al., 2010; Shikazono et al., 2009). Thus, much of the DNA lesions induced by IR, in contrast to endogenous ones, may be accompanied by loss of encoded information; they contain more complex groups at break ends.

Quantitative analysis of DNA damage in a single mammalian cell, immediately after its exposure to IR with low-LET at a dose of 1 Gy shows the formation of about 40 DSB and 40 ICL, about 150 DNA-protein crosslinks (DPC), some 2000 base modifications, about $3000 \mathrm{AP}$ sites, damaged deoxyribose residues, SSB and alkali-labile sites (Ward, 1988; Gaziev, 1999). Many of IR-induced lesions are not randomly distributed but form, to a large extent, clusters, that is, they can be located in close proximity to each other. Typically, cluster DNA damage results from local matches of two or more single lesions within 1-2 turns of the DNA helix (Hada and Georgakilas, 2008; Sage and Harrison, 2011). A clustered DNA damage may represent damaged bases, AP sites located next to DSB or SSB. Clustered injuries are generated both at high and at low doses of IR (Sutherland et al., 2000). Clustering of DNA damage occurs on a large scale and depends on DNA packing and the structural state of chromatin in the cell nucleus during exposure of cell to IR. Most pronounced clustering occurs when the ionization tracks run along the chromatin fiber. In this case the clustered damage may cover DNA regions of about 2 thousand bp (Radulescu et al., 2004; Regulus et al., 2007). It was shown that clustered DNA damage in the form of modified bases, AP sites and SSB, localized close to each other, is 4-8 times more than the amount of DSB in DNA of mammalian cells after radiation exposure (Radulescu et al., 2004; Hada and Georgakilas, 2008). Such clustered lesions are turned to DSB in the initial stage of BER functioning (Asaithamby et al., 2011). DSB can be considered as a kind of clustered DNA lesions, in which the SSB or gaps are formed on opposite chains in the immediate vicinity. DSB may be formed not only directly but also indirectly (via production of ROS) as a result of closely spaced two or more SSB on opposite strands within approximately 10-20 bp. In addition, IR induced DSB may contain long single-stranded overhangs on the ends (Eccles et al., 2010). The significant amount of IR-induced ICL in cellular DNA can also be viewed as the result of clustered or multiple lesions (Gantchev et al., 2009). Formation of long gaps can also occur as a result of the clustered arrangement of SSB and the damaged DNA bases in chromatin structure (Gulston et al., 2004). 
It is well established that the level of clustering of DNA damage and their complexity increase with increasing LET of radiation (Terato and Ide, 2004; Sage and Harrison, 2011). For low-LET IR, this clustering occurs mainly on small sites of DNA and nucleosomes in the chromatin. High-LET radiation can produce in DNA several DSB close to each other (Radulescu et al., 2004). The relationship between various DNA lesions in cells exposed to radiation with high-LET is changing in favor of more complex DNA damage (Sutherland et al., 2002; Sage and Harrison, 2011). Low-LET radiation, $\gamma$-rays in particular, causes in DNA DSB, 30\% of which represent cluster formations. High-LET radiation, such as a-rays, yields more than $90 \%$ of DSB with ends carrying additional single lesions (Terato and Ide, 2004; Hada and Georgakilas, 2008). It was shown that in the case of irradiation of cells with protons (LET $9.2 \mathrm{keV} / \mathrm{m}$ ), 45\% of the resulting SSB in the DNA are accompanied by additional damage of bases in close proximity to these breaks, and this value increases to $78 \%$ after exposure of these cells to a-particles (LET $129 \mathrm{keV} / \mathrm{m}$ ) (Terato and Ide, 2004). Other studies have also shown the formation of more complex DNA lesions after exposure of cells to high-LET radiation (Semenenko and Stewart, 2004). Clustered DNA damage occurs after irradiated of cells by low doses. So it was shown the linear dependence of the induction of clustered DNA damage in human primary fibroblast on the dose (10-100 cGy) X-rays (Das et al., 2011). Note that the probability of endogenous clustered DNA damage is extremely low (Bennett et al., 2004).

It is well known that the choice of repair pathways, as well as the efficiency and accuracy of this process in the cell, depend on the type of injuries and their complexity. Many DNA lesions, such as SSB, AP sites, base modifications, induced by IR or emerging endogenously in the cell, are mainly repaired by the BER pathway. The repair of DNA-protein crosslinks in mammalian cells occurs mostly by homologous recombination (Ide et al., 2011). The most complex pathways of DNA repair are responsible for correction of DSB and ICL induced by IR (Lieber, 2010; Dextraze et al., 2010).

Repair of a single lesion within a cluster may lead to formation of additional DSB or cause errors, which are critical for cell survival, mutagenesis, and malignization. There is literature evidence that DSB repair in cells irradiated with high-LET IR is less efficient than in the case of low-LET radiation. This is due, exclusively, to the complexity of these breaks (Heilmann et al., 1993; Dianov et al., 2001). Tandems of different single lesions with DSB may further complicate the repair of both types of injury and increase their biological significance (Sutherland et al., 2000; Sage and Harrison, 2011).

Thus, it is believed that the complexity and clustering are the most important specific characteristics of radiation-induced DNA lesions, which distinguishes them from the endogenous damage. Now also clear that a genetic effects and lethality of IR is not just related to the types of DNA lesions introduced, but also to how the damage is distributed in the DNA (Sage \& Harrison, 2011). The most critical DNA injuries induced by IR may be thought to be DSB, ICL, damage due to destruction of the replication fork and formation of long single-stranded gaps. A complex radiation-induced DNA lesion is a serious burden for constitutive cellular repair systems. To repair such damage requires additional activation of many processes. In contrast to endogenous damage, repair of radiation-induced damage is accompanied by significant errors.

\section{Mechanisms of cell response to DNA damage}

Since DNA is constantly damaged by the action of endogenous and exogenous factors, living organisms in their evolution developed complex systems that monitor the structural 
integrity and stable operation of the genome. The components of these systems are able to recognize the most critical DNA lesions and to trigger a cascade of multiple molecular and biochemical reactions for the safety of genetic information. The extensive network of these reactions is activated as critical DNA lesions appear and is included in cell cycle regulation, DNA repair, reconstruction of chromatin, induction of transcription and cell death. The total sum of these reactions in the cell is called DNA damage response (DDR) (Kastan and Bartek, 2004).

Recent results of many studies on allow us to understand the mechanisms of DDR development in the cells after its exposure to IR, although much is still not clear. The development of DDR depends on many of proteins with different functions. These proteins have been classified as sensors, mediators, transducers, and effectors (Ding et al., 2005; Harper and Elledge, 2007). Although this classification is an arbitrary one, and the differences between protein groups are sometimes blurred, it facilitates our understanding of the mechanisms of process development.

The activation of cell cycle checkpoints is of vital importance for an effective DDR. The induction of gene expression is also associated with the development of the whole complex of DDR events. And the expression level of many genes may change depending on IR dose and the time after irradiation of cells (Ding et al., 2005; Taki et al., 2009; Ghandhi et al., 2011). These processes are influenced by microRNAs, the endogenous gene regulators (Hu and Gatti, 2011). DDR is also accompanied by reconstruction of chromatin by modifying proteins, which contributes to the recognition of DNA damage and repair (Pandita and Richardson, 2009; Misteli and Soutoglou, 2009).

DDR is regarded as an anti-carcinogenic mechanism (Costes et al., 2010), it is associated with a wide range of essential cellular processes and contributes to prevention of multiple human diseases (Kastan and Bartek, 2004; Bartek et al., 2007). Cells, deficient in different components of DDR development, have an increased sensitivity to IR and other DNAdamaging agents, and many of these defects are causative factors of human diseases (Jackson and Bartek, 2009; Jeggo, 2010).

The development of DSB-initiated DDR has been studied most of all. However, the development of DDR may also occur with other critical DNA lesions involving the same protein hierarchy as in the case of DSB (Fig. 1). At least, phosphorylated proteins, the characteristic markers for the development of DDR are also registered in case of ICL, destruction of replication fork and other complex DNA lesions of cells exposed to IR, UV light, chemical genotoxicants, as well as heat or adenovirus infection (Nagy and Soutoglou, 2009; Olive and Banath, 2009; Nichols et al., 2009; Callegari et al., 2010; Takahashi et al., 2010). Although it is possible that DDR markers detected on such complex injuries are caused by occurrence of DSB as an intermediate stage in the process of their repair.

DDR develops rapidly by migration of the protein complex MRN, which consists of three subunits (Mre11-Rad50-Nbs1), and the 9-1-1 complex, consisting also of three proteins (Rad9-Rad1-Hus1), which are the primary sensors of DSB and other critical DNA lesions (Parrilla-Castellar et al., 2004; Rupnik et al., 2010). Along with the complexes MRN and 9-11, the protein CtIP (tumor suppressor) also binds to damaged DNA sites (You and Bailis, 2010). The protein CtIP, by interacting with the subunit Mre11 (endonuclease), stimulates the activity of the complex MRN (Rupnik et al., 2010; You and Bailis, 2010). The complex MRN and the protein CtIP, when interacting with a DNA sequence containing DSB may unwind and resects the terminal sequences with removal of adducts and formation of short 
single-stranded fragments at the $3^{\prime}$ ends, which can bind proteins of the 9-1-1 complex (Kastan and Bartek, 2004; You and Bailis, 2010).

The signals of occurrence of critical injuries, DSB in particular, and of the interaction of sensory proteins with damaged DNA regions are received by other transducer proteins: ATM/ATR-kinases from the family of phosphatidylinositol-3-kinase-like protein kinases. In the interaction of the MRN complex with a broken site of DNA, a rapid (within tens of seconds or one minute) recruitment of ATM (ATM, ataxia-telangiectasia mutated) to the same site takes place. ATM is a major kinase of the early response to a signal from the IRinduced DSB of DNA (Kastan and Bartek, 2004; Borde and Cobb, 2009). In this case, ATM, which in intact cells is in the form of a dimer, undergoes activation by autophosphorylation and splits into monomers. The monomer ATM molecules are further activated as a result of interaction with the C-terminal of the Nbs1-subunit (a protein mutated in the Nijmegen syndrome) of the MRN complex (Borde and Cobb, 2009; Huertas, 2010).

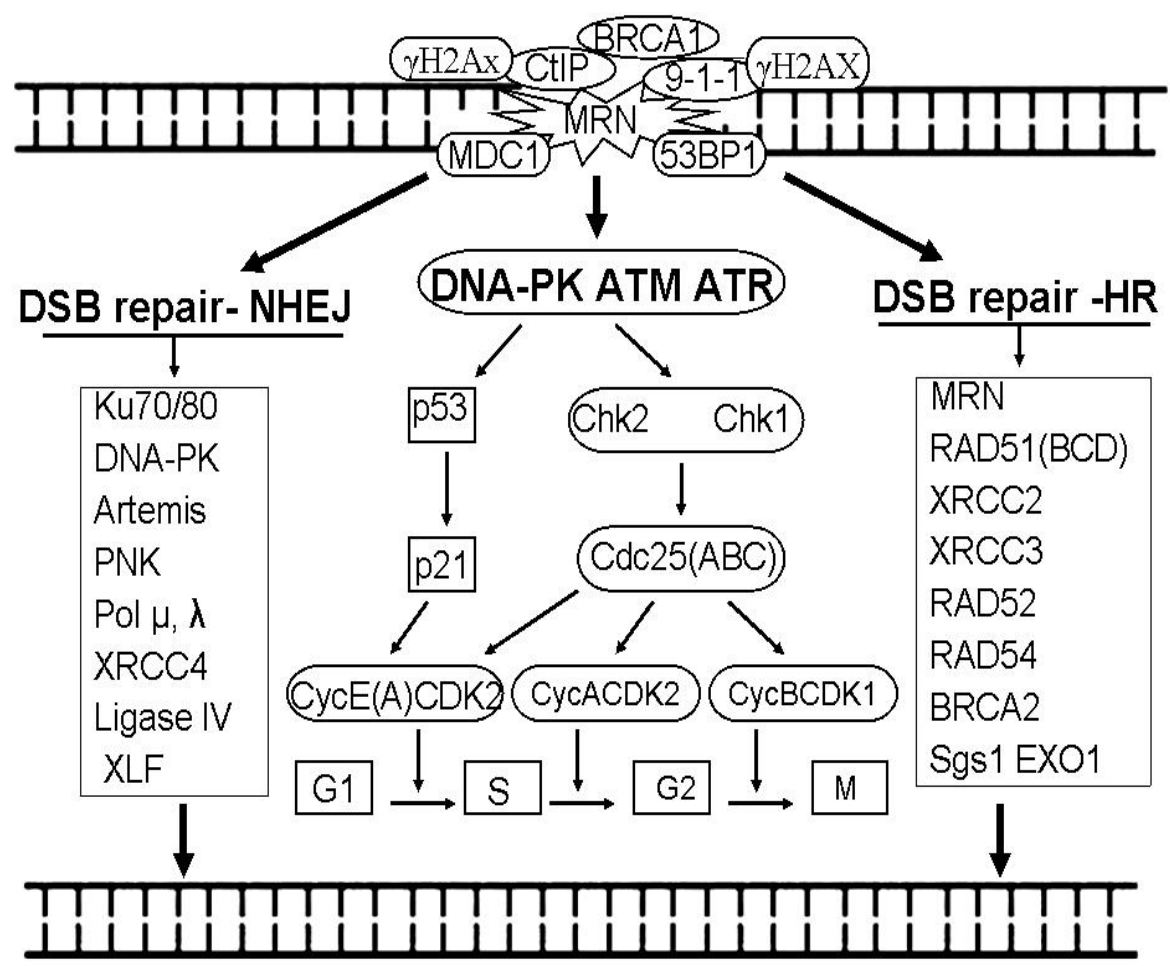

Fig. 1. A simplified scheme of development of cellular response to DNA damage (doublestranded break) in mammalian cells exposed to ionizing radiation. Here are the main proteins involved in the damage recognition, signaling and reparation. At the heart of the scheme - the direction of activation of cell cycle checkpoint that arrest cell transition in phases until the completion of DNA repair. Left and right of the scheme shows the basic components of DSB DNA repair by two principal pathways: non-homologous end-joining (NHEJ) and homologous recombination (HR). Explanations are given in the text. 
Activated ATM stimulates ATP-dependent unwinding of terminal regions to form singlestrand DNA. It has been also shown that, due to resection of DSB ends by MRN and CtIP, small overhanging ends of single strand DNA are formed (Huertas, 2010). Subsequent action of proteins ExoI and Dna2 (nucleases) alone or in combination with Sgs1 (helicase), create more extensive sequences of single-strand DNA (Lee and Paull, 2007; Lavin and Kozlov, 2007).

The formation of single-strand DNA is a signal that is perceived by ATR-kinase (ATMrelated Rad3), which is also activated by autophosphorylation and then phosphorylates itself a set of proteins (on serine and threonine) participating in DDR (Mimitou and Symington, 2008; Cimprich and Cortez, 2008). Actually, after the DSB end resection has occurred and single-stranded oligonucleotides at these ends has appeared, the activity of ATM kinase is suppressed and ATR-kinase is activated through its interaction with singlestrand DNA. In the process of replacing of ATM by ATR, the sensory complexes MRN, 9-11, RAD17-RFC and TopBP1 are involved (Cimprich and Cortez, 2008). The single-strand DNA regions are loaded by molecules of the protein RPA, participating in DNA replication and these proteins provide protection of single-strand DNA from nuclease attacks. ATRkinase, in conjunction with the protein ATRIP (ATR binding protein), move to the regions with which RPA molecules are associated and covers single-strand DNA (Zou \& Elledge, 2003; Smits et al., 2010).

Thus, ATR, like ATM, is a transducer of the signal received from the sensors of DNA damage. ATR-kinase can be activated in cells irradiated in the S-phase (when the damage blocks DNA replication) (Cimprich and Cortez, 2008; Smits et al., 2010). Although ATM is crucial in the primary response of the cell to DNA damage and in the subsequent activation of ATR, the latter has been proved to be more important for the survival of mammals. Deficient ATR in mouse or human cells leads to cell cycle arrest or to cell death, even in the absence of exogenous DNA damage (Falck et al., 2005).

In response to critical DNA damage in mammalian cells, not only ATM and ATR are activated, but also the catalytic subunit (cs) of DNA-dependent protein kinase (DNA-PKcs). These three kinases phosphorylate more than 700 proteins (Falck et al., 2005; Matsuoka et al., 2007). Among them are histone $\mathrm{H} 2 \mathrm{AX}$ molecules, which after phosphorylation $(\gamma \mathrm{H} 2 \mathrm{AX})$ contribute to recruitment of other proteins to the damaged region of DNA. The major proteins recruited for the damaged region of DNA are mediator proteins of DDR, such as Nbs1, BRCA1, Artemis (nuclease), 53BP1 (p53 binding protein), RAD51, MDC1, MCPH1/BRIT1, ubiquitin ligase RNF8, the complex RNF168/RIDDLIN, RAD17, RPA, ATRIP, the complex Rad9-Rad1-Hus1, TopBP1, Claspin and other target factors able to be phosphorylated. Many mediator proteins, such as $\mathrm{YH} 2 \mathrm{AX}, \mathrm{BRCA1}$, MDC1, Claspin and 53BP1 usually function in coordination with other DDR factors, contribute to their activation (Matsuoka et al., 2007; Cimprich and Cortez, 2008; Smits et al., 2010).

Thus, the protein MDC1 binds to $\gamma \mathrm{H} 2 \mathrm{AX}$, and the complex MRN recruits ubiquitin ligase RNF8 for the damage region to form a structure that holds the proteins RNF168, BRCA1 and $53 \mathrm{BP} 1$ in the DSB region of DNA. In this system, the protein MDC1 (checkpoint mediator) plays a major role in forming the molecular scaffold, which stabilizes the binding of the MRN complex to the damaged region of DNA and the activated ATM (Matsuoka et al., 2007; Kolas et al., 2007). The protein MDC1, along with $\gamma \mathrm{H} 2 \mathrm{AX}$, also promotes the assembly of repair and checkpoint proteins in the chromatin portion with damaged DNA and contributes to its transition to a more relaxed conformation (Goldberg et al., 2003; Stewart et al., 2003; Kolas et al., 2007). 
Numerous proteins localized, along with histone $\mathrm{\gamma H} 2 \mathrm{AX}$, in DNA regions with DSB form large local structures (foci). These nuclear structures formed on DNA sites with DSB, or, as they are often referred to, radiation-induced foci (RIF), may cover a nucleus area of 1.7-2 $\mu \mathrm{m}^{2}$ or DNA up to $15 \times 10^{6}$ bp (Rogakou et al., 1999; Celeste et al., 2002; Wang and Elledge, 2007). The number of RIF in the nuclei can be determined by immunofluorescence, with matching specific antibodies against proteins that make up these foci, such as histone $\gamma \mathrm{H} 2 \mathrm{AX}$ or 53BP1. It has been well established that the number of RIF determined by means of $\gamma \mathrm{H} 2 \mathrm{AX}$ or other proteins, characterizes both the number of DSB in DNA and the state of the kinetics of their repair (Celeste et al., 2002; Wang and Elledge, 2007; Löbrich et al., 2010). These foci are eliminated from the chromatin as a result of dephosphorylation of $\gamma \mathrm{H} 2 \mathrm{AX}$ after DSB repair (Svetlova et al., 2010).

\section{Activation of cell cycle checkpoints}

It is well known that cell cycle progression is controlled by a series of checkpoints. If this system is active enough, the entry of cells with damaged DNA into the next phase will be arrested until the completion of its repair. However, if the checkpoint system is not activated, the entry transition of cells with critical DNA damage into another phase of the cell cycle can be completed either by fixation of chromosomal disorders or by apoptosis (Costes et al., 2006; Harrison and Haber, 2006; Yamauchi et al., 2008). Therefore, the arrival of a signal to activate the cell cycle checkpoint is a critical event in the development of the complex network of DDR. The signal to activate the cell cycle checkpoint is transmitted by ATM/ATR inverters, which themselves take this signal from the sensors of DNA damage.

Activation of the checkpoint occurs by the following main mechanisms (Fig. 1). In the scheme involves the activation of cell cycle checkpoint due to DSB. ATM and ATR take signals from sensor proteins capable of recognizing the critical DNA damage, and then phosphorylate the effector kinases Chk1 and Chk2 (checkpoint-kinases 1, 2) (Costes et al., 2006; Yamauchi et al., 2008). Activation of Chk2 occurs through its phosphorylation by ATM kinase at the amino acid T68, followed by oligomerization and autophosphorylation at T383 and T387 (Harrison and Haber, 2006).

Activation of Chk1 occurs through its phosphorylation by ATR-kinase at amino acids S317 and S345 (Cook, 2009). ATP-mediated activation of the checkpoint occurs also due to the destruction of the replication forks (Warmerdam et al., 2010). In this case, as shown by biochemical data ATR in complex with ATRIP, binds to RPA-coated single-strand DNA (Zou \& Elledge, 2003). This obviously protects the single-strand DNA against nuclease attack.

Activated kinases Chk1 and Chk2 in turn phosphorylate other proteins-phosphatases (Cdc25A, Cdc25V, Cdc25S), which control the activity of cyclin-dependent kinases (CDKs) by splitting out their phosphate groups. However, the phase-specific CDKs are active only in association with cellular cyclins. Thus, in the cell transition G1/S a cyclin E (A)-CDK2 complex is functioning, within the $S$ phase the complex cyclin A-CDK2 and in the G2/M transition - the cyclin B-CDK1 complex (Harrison and Haber, 2006; Bartek and Lukas, 2007). After phosphorylation, the phosphatases Cdc25 (ABC) lose their activity and undergo ubiquitin-mediated proteosomal degradation. Under conditions of suppressed phosphatase activity, the CDK dephosphorylation stops and there occurs a complete phosphorylation of 
the phase-specific cyclin-CDK complexes, which block the G1/S and G2/M phase transitions of the cells. In this case, the initiation of replication of new DNA replicons in the S-phase is also blocked (Bartek and Lukas, 2007; Stracker et al., 2009).

There is also another p53-dependent pathway to activate the checkpoint. Thus, the chain of reactions ATM $\rightarrow$ CHK2 (ATR $\rightarrow$ CHK1) $\rightarrow$ p53 $\rightarrow$ MDM2 $\rightarrow$ p21 $\rightarrow$ cyclin-CDK is also one of the main pathways to arrest G1/S and G2/M transitions in the presence of DNA lesions. In this chain of reactions (with stabilization of p53 by phosphorylation) there occurs the activation of $p 21$ gene expression (Chung and Bunz, 2010). Accumulation of protein p21 leads to inhibition of the activity of cyclin E (A)-CDK2 and cyclin B-CDK1complexes. It should be noted that the p53-independent (CHK1/CHK2 $\rightarrow$ Cdc25 (ABC) pathway of checkpoint delays the G1/S transition for no more than a few hours, while the p53dependent pathway extends significantly the block of the G1phase (Niida et al., 2010; Freeman and Monteiro, 2010; Shibata et al., 2010).

Thus, the signaling of DNA damage perceived by ATM/ATR, is transmitted to the key effectors of checkpoint activation - Chk1 and Chk2 kinases, and the subsequent reaction chain provides an arrest of cell cycle progression prior to the completion of DNA repair. After the repair of critical DNA damage has been completed, the checkpoints can be switched off and the cell cycle progression resumed in the cell.

\section{Repair of double strand breaks and interstrand cross-links in DNA}

The ATM/ATR signaling, simultaneously with the activation of cell cycle checkpoints, activates the repair process by induction of repair protein transcription, mobilization of other components involved in the repair and by modification of chromatin proteins (Costes et al., 2010; Warmerdam and Kanaar, 2010). This can be seen during destruction of the replication forks, induction of DSB, ICL and other complex lesions. So, DNA replication forks are stalled by many DNA lesions, activating checkpoint proteins that stabilize stalled forks (Allen et al., 2011). The activation of the checkpoint and the repair of critical lesions are interrelated. The efficiency of repair of such DNA lesions depends on their complexity. Let us consider pathways to repair the two types of critical DNA damage: DSB and ICL. The repair of DSB and ICL are important for maintaining the physical and genetic integrity of the genome. Moreover, in humans it is associated with the prevention of diseases such as cancer.

\subsection{Repair of DNA double strand breaks}

DNA DSBs induce breakage of chromosomes. In the course of cell division, chromosome fragments can unevenly be redistributed among daughter cells, so that they can generate translocations, i.e. appear in other parts of the genome, where they are not supposed to be. Deletions or translocations of chromosome fragments lead to inactivation of tumor suppressor genes or activation of oncogenes. Both events may initiate carcinogenesis in the surviving cells (Hoeijmakers, 2001; Halazonetis, et al., 2008; Natarajan \& Palitti, 2008).

In mammalian cells, the repair of DSBs in DNA proceeds by two main pathways: by nonhomologous end-joining (NHEJ) and by homologous recombination (HR) (Fig. 1) (San Filippo et al., 2008; Lieber, 2010). The repair of DSBs through NHEJ occurs in the G0, G1, and G2 phases of the cell cycle whereas the mechanism of HR may function in the S and G2 phases, because in these phases two sister chromatids are present. However, if in the course 
of $\mathrm{S}$ and G2 phases there is no homologous variant alongside the damaged DNA, then the mechanism of HR cannot operate. In haploid cells in the stationary phase, in the absence of a homology of damaged DNA, the DSB repair by HR pathway is likewise impossible (Heyer et al., 2010). Also, in the case of non-dividing diploid cells, the occurrence of the damaged DNA region in the vicinity of a homologous donor is quite problematic. Moreover, the repair of IR-induced DSB by HR mechanisms can not always be successful since IR induces cluster lesions which produce complex adducts at DNA ends (Shikazono et al., 2009). Probably, the reunion of most DSB in DNA regions not involved in replication during the Sphase is accomplished by NHEJ. Therefore, the repair of DSBs by an error-prone NHEJ mechanism in the cells of IR-exposed mammals may be prevailing throughout the cell cycle (Mahaney et al., 2009; Lieber, 2010).

The repair of DSBs by HR mechanisms is more accurate because homologous regions of sister chromatides are used as a template to restore the broken DNA strand (San Filippo et al., 2008; Heyer et al., 2010). This process is initiated by binding of the complex MRN (Mre11/Rad50/Nbs1) to the ends of DSBs. Together with the protein CtIP, the complex MRN provides the initial resection of broken DNA ends while forming small 3' overhanging of single-strand DNA (Sartori et al., 2007). Nucleases ExoI or Dna2 in combination with Sgs1- helicase produce, by further resection of the $5^{\prime}$ end of broken DNA strand, longer $3^{\prime}$ overhangs - single-strand regions covered with RPA molecules. Then the protein Rad51, with the participation of BRCA2, replaces RPA on single-strand DNA to form a nucleoprotein filament. Thus, recombinant 3 ' single-strand tails are formed at broken DNA ends. Hereafter, these single-strand regions invade, with the help of their associated protein Rad51, the homologous double-strand DNA-template to generate homologous DNA duplex (Modesti et al., 2007; Cejka et al., 2010). Then the branch migrates with the formation of so called Holliday structures, which favors error-free DNA repair (San Filippo et al., 2008; Cejka et al., 2010).

In mammalian cells, this process is mainly provided by multiple proteins encoded by a group of the gene family Rad (RAD51, RAD52, RAD54, RAD55, RAD57, RAD59, and RDH54). In addition to the products of these genes, involved are also nucleases (Exol, Sae2, Rad1-Rad10) helicases (Sgs1, Srs2), topoisomerase (Top3), polymerases (Pol32) as well as ligases, which terminate the repair (San Filippo et al., 2008; Cejka et al., 2010).

Unlike DSB repair by HR, the repair mechanisms of NHEJ remain in many respects unclear. The repair of DSBs by NHEJ is rather complex and dynamic and requires coordinated interactions of many active proteins throughout the process. Repair of a certain number of DSBs through NHEJ can occur independently of ATM activation, whereas the repair of the other part of DSB is extremely ATM-dependent (Jeggo, 2009; Warmerdam and Kanaar, 2010).

On the other hand the DSB repair occurs in DNA not only in the major, "classic" pathway NHEJ, but also in an "alternative" pathway - by binding the ends of terminal microhomologies (Haber, 2008; McVey and Lee, 2008). In this case, microhomologies of about $4 \mathrm{bp}$ can be formed at broken DNA ends. This kind of DSB repair is likely to occur in DNA regions that contain repetitive sequences. This process does not depend on $\mathrm{Ku}-$ proteins, the complex of ligase IV-XRCC4 (the most important components of NHEJ), but it depends on Nbs1 and Fen-1. In addition, it involves proteins of the system for mismatch repair: MLH1 and MSH2 (McVey and Lee, 2008). However, repair by binding the ends of terminal microhomologies, perhaps, does not play any significant role in stabilizing the genome of mammalian cells (Lieber, 2010). 
The main pathway to repair DSBs by NHEJ is initiated by binding heterodimer Ku70/80 protein complexes to both ends of broken DNA molecules (Pardo et al., 2009). The complex $\mathrm{Ku} 70 / 80$ protects the ends of DSB from early degradation and ligation, and also contributes to recruitment of DNA-PK $\mathrm{CS}_{\text {to }}$ broken DNA region. DNA-PK $\mathrm{CS}_{\mathrm{C}}$ when associated with both ends of DSB and with the dimer Ku70/80 is activated by autophosphorylation (Costantini et al., 2007). DNA-PKcs and $\mathrm{Ku}$ heterodimer together form the complex that plays key roles in the repair DSB through the NHEJ pathway.

DNA-PK $\mathrm{Cs}$ and ATM phosphorylate a number of proteins involved in the process of NHEJ of DNA. When captured by the complex $\mathrm{Ku} 70 / 80 / \mathrm{DNK}-\mathrm{RK}_{\mathrm{CS}}$, both ends of DNA are processed by various enzymes for removal of terminal groups or adding nucleotides to these ends. This stage of processing in the repair by NHEJ is believed to be responsible for errors resulting from losses and additions of nucleotides at the sites of DNA DSB rejoining (Mahaney et al., 2009; Lieber, 2010). In the processing of broken DNA ends, the following enzymes are involved: the nuclease Artemis (Yannone et al., 2008), the DNA polymerases of the family $X$ (Pol $\mu$ and Pol $\lambda$ ) (Moon et al., 2007), and the terminal deoxynucleotidyl transferase (Mahaney et al., 2009), as well as polynucleotide kinase having both the kinase and phosphatase activities (Bernstein et al., 2008). Also, some other substances participate in the process, such as aprataxin (APTX) which catalyzes the removal of AMP groups at the 5 'ends of the DSB (Rass et al., 2008), the PALF-factor, and the protein cernunnos (XLF), which interact with XRCC4 in the activation of the DNA-ligase complex XRCC4/DNK-ligase IV/XLF (Tsai et al., 2007; Yano et al., 2009).

The final stage of DSBs repair by NHEJ is binding the broken DNA ends by the ligase complexes (Mahaney et al., 2009; Heyer et al., 2010). In the presence of Ku proteins, the full ligase complex (XRCC4/DNK-ligase IV/XLF) can couple incompatible DNA ends and, more effectively, blunt ends of breaks (Gu et al., 2007).

Thus, we can assume that the main mechanism for repairing DNA DSB induced by low doses of IR is the NHEJ pathway.

\subsection{Repair of interstrand cross-links of DNA}

The interstrand cross-links (ICLs) are highly toxic DNA lesions that block replication and transcription by inhibiting DNA strand separation, can also retard the repair of monoadducts in DNA. ICL may provoke genomic instability, chromosomal aberrations, and cell death (Noll et al., 2006; Dextraze et al., 2010). Many studies on the formation and repair of DNA ICL in the cells are related with the influence of chemical agents. As for the data on the repair of IR-induced ICL, they are rather limited. This is most likely caused by methodological difficulties of their acquisition against a variety of other IR-induced DNA lesions and, in particular, because of their association with clustered lesions (Ding and Greenberg, 2007; Hong et al., 2007; Gantchev et al., 2009). It should be noted that the cells of patients with the syndrome of Fanconi anemia (FA) are characterized by genome instability, and predisposition to malignancy, and by increased sensitivity to IR due to their inability to repair ICL of DNA (Alter, 2002; Kuhnert et al., 2009).

ICL initiate the development of DDR with the activation of cell cycle checkpoints, with transmission of the signal along the chain ATM/ATR $\rightarrow$ Chk1/Chk2 $\rightarrow$ Cdc25 (A, B, C) $\rightarrow$ cyclin-CDK (Wu and Vasquez, 2008; Ben-Yehoyada et al., 2009; Vasquez, 2010). It has been also shown that the induction of ICL in DNA is accompanied by formation of $\gamma \mathrm{H} 2 \mathrm{AX}$-foci (Huang et al., 2004; Mogi and Oh, 2006; Mogi et al., 2008). Moreover, $\gamma \mathrm{H} 2 \mathrm{AX}$-foci occur in 
the nuclei of cells after their treatment with compounds that cause ICL, but not directly induce DSB in DNA (Huang et al., 2004; Mogi and Oh, 2006; Olive and Banath, 2009). However, this does not exclude that $\gamma \mathrm{H} 2 \mathrm{AX}$-foci in the nuclei of cells exposed to agents that induce ICL are caused by DSB, since ICL repair processes are accompanied by DSB generation (Olive and Banath, 2009; Sczepanski et al., 2009; Muniandy et al., 2010).

Removal of ICL from replicating and non-replicating DNA of mammalian cells can occur in two ways (depending on cell cycle phase) with the participation of enzymes produced by a number of repair systems, as well as proteins produced by Fanc genes (mutated genes in patients with the syndrome FA) (Moldovan and D'Andrea, 2009; Thompson and Hinz, 2009; Knipscheer et al., 2009). Thus, in the phases G0, G1 of the cell cycle, the removal of ICL is mostly provided by the system of nucleotide excision repair (NER), which ensures the global genome repair and the transcription-related repair (Sczepanski et al., 2009; Wood, 2010). Through this pathway, the repair of ICL begins with recognition of the injury with the complex XPC-HR23B. However, the endonuclease complex ERCC1-XPF is a key factor in the repair of ICL on non-replicating DNA (Cole et al., 2010). This complex, while inducing breaks with 5 'and 3' ends on both sides of ICL on one strand, creates a gap that can serve as a site for DNA synthesis bypassing the damage (Cole et al., 2010; Liu et al., 2010), after processing DNA break ends by the nuclease DCLRE1A/SNM1A. The duplex formed as a result of the DNA synthesis bypassing the damage and bearing cross-link remains on one strand becomes a substrate for the classical system of NER, which provides the final stage of removal of ICL from non-replicating DNA. This process is accompanied by a loss of 11-14 $\mathrm{bp}$, and is concluded with formation of DSBs which can be restored by HR (Peng et al., 2010; Legerski, 2010; Muniandy et al., 2010).

The removal of ICL in the S phase of cells proceeds by a different pathway. Collision of the replication fork with ICL triggers a cascade of reactions, which promotes removal of the cross-link and restoration of DNA replication (Moldovan and D'Andrea, 2009; Thompson and Hinz, 2009; Knipscheer et al., 2009). Recent studies have shown that the main function of FA-proteins is associated with activation of signaling from DNA damage and repair of ICL in the S-phase of the cell cycle (Knipscheer et al., 2009; Liu et al., 2010). The removal of ICL from replicating DNA is accompanied by activation of cell cycle checkpoints (Noll et al., 2006; Legerski, 2010). ATR-dependent activation of the major FA- complex (A-C, E-G, L, and FAAP100) is the central event of repair of ICL that blocks the replication fork. The occurrence of ICL in the replication fork is recognized by several FA-protein complexes, including FANCM and FAAP24, which provide access of other proteins to the damage to repair it (Grillari et al., 2007; Dextraze et al., 2010).

An important role in these events is played by the complex FANCI/FANCD2, which binds to DNA sites with ICL (Smogorzewska et al., 2010). This complex, in collaboration with the Tip60 protein, also contributes to remodeling of chromatin sites with damaged DNA (Hejna et al., 2008). When this complex encounters a restructured DNA replication fork, due to localization of ICL, it is phosphorylated by ATR/ATRIP kinases localized in ssDNA, together with the protein RPA. The phosphorylated complex FANCI/FANCD2 is fully activated after its monoubiquitination by the multi-subunit ligase E3. The activated complex FANCI/FANCD2 moves to DNA sites with ICL. This activated complex, together with other FA-protein complexes FANCD1/BRCA2 and FANCN/PALB2 is involved also in a subsequent stage of recovery of broken replication fork via HR (Knipscheer et al., 2009; Liu et al., 2010; Smogorzewska et al., 2010). Protein complexes, such as MRN, Snm1B and MUS81-EME1/2, also bind to the DNA sites of the replication fork blocked by ICL. The last- 
named complex has a nuclease activity, it makes an incision on one side, flanking the ICL, and the endonuclease ERCC1-XPF makes the second incision, on the other side of the crosslink (Knipscheer et al., 2009; Liu et al., 2010; Cole et al., 2010). As a result of these endonuclease attacks, one strand gets free of the cross-link and the ends of the resulting gap undergo processing. Then the gap is filled due to DNA synthesis (bypassing lesions on the template strand bearing cross-link remains) with the participation of DNA polymerases: pol $\zeta$, polk, polı, polN, poln and Rev1 (Ho and Schärer, 2010). After filling in the gap, the cross-link remains bound to the second strand undergo excision by NER enzymes. The repair of DSB formed during removal of ICL from the replicating DNA with the participation of FA-proteins, is also provided by the mechanism of HR (Hinz, 2010).

\section{Low efficiency of repair of critical DNA damage induced by low dose radiation}

Over the last 10-15 years evidence has been accumulated pointing to that the responses of mammalian cells to small and large doses of ionizing radiation may be qualitatively different in a number of characteristics, including the development of DDR. First of all, these are the reactions of cells to critical DNA damage, such as signals to activate checkpoints, DNA repair, chromatin reconstruction and postradiation changes in the expression of many genes. To this must be added epigenetic effects, induced genome instability and the bystander effect (Mullenders et al., 2009). The factual data on these characteristics obtained for low-dose-irradiated organisms do not fit into the model of the linear dependence of biological effects on IR dose (Hayes, 2008; Averbeck, 2009; Ulsh, 2010).

In this section we analyze the results of a number of independent studies on DDR development, on the signaling to activate cell cycle checkpoints and on the repair efficiency of critical DNA lesions induced by low-dose or low-intensity radiation in mammalian cells.

\subsection{Inadequate activation of cell cycle checkpoint at low-dose radiation}

For the most part, the data on this subject relate to DNA DSB. Much of the evidence presented earlier (before the advent of more sensitive methods) on assessment of IRinduced DNA DSB and their repair, were obtained in studies using high radiation doses. These methods, although quite adequate, appeared not sensitive enough to detect these lesions and to follow the kinetics of their repair in cells exposed to low-dose radiation. Actually, sensitive methods to assess DSB that arise under the influence of low dose radiation have been developed in studies of DDR. An important step in this direction was the development of methods using fluorescent antibodies to phosphorylated proteins, specifically localized in discrete nuclear radiation-induced foci (RIF) at DNA sites containing DSB. RIF can be visualized and counted under a microscope. These methods are most commonly based on the use of fluorescent antibodies specific for phosphorylated proteins involved in RIF formation, such as histone H2AX ( $\gamma \mathrm{H} 2 \mathrm{AX})$, ATM-kinase (pATM), 53BP1 (p53BP1) and others. These RIF localized in the nuclei of irradiated cells, enable counting of DSB, and, from reduction of their number, judging the kinetics of their repair, as well as analyzing other critical injuries that can be realized in the form of DSB. Thus, the determination of DNA DSB induced by low-dose radiation (1-100 mGy), has become possible by analysis of histone $\gamma \mathrm{H} 2 \mathrm{AX}$ immunofluorescence in RIF formed by accumulation of their molecules at DSB sites of DNA within the chromatin (Celeste et al., 2002; Wang and Elledge, 2007; Nagy and Soutoglou, 2009; Löbrich et al., 2010; Redon et al., 2011). This 
method also allows determination of the endogenous level of DSB in cellular DNA. Currently, RIFs are regarded as a highly sensitive biomarker to assess the damage to cell genome due to radiation or other genotoxic effects, the method can be applied in the clinics (Sedelnikova et al., 2008; Lassmann et al., 2010).

By the method of identifying RIF by $\gamma \mathrm{H} 2 \mathrm{AX}$ it was revealed that DSB induced in DNA of non-dividing primary human fibroblasts, after their exposure to low doses of radiation $(\sim 1$ mGy), remained non-repaired for many days. On the other hand, the number of DSB in cells irradiated with low doses, decreased in the postradiation period up to the control level if these cells were allowed to proliferate after irradiation. The authors suggested that this effect might be due to elimination of cells with non-repairable DSB from the total cell population by apoptosis (Rothkamm and Löbrich, 2003). In a recent study, by analysis of RIF marked at phosphorylated proteins $\gamma \mathrm{H} 2 \mathrm{AX}$, ATM (pATM) and 53BP1, DNA DSB repair was monitored in human fibroblasts exposed to IR at doses between 2.5 to 200 mGy (Grudzenskia et al., 2010). The kinetics of disappearance of RIF recorded in these cells during post-radiation time depended on irradiation dose. The repair of DSB in low-dose irradiated cells was significantly lower than in cells irradiated with higher doses. In the case of exposure of cells to $2.5 \mathrm{mGy}$, the loss of RIF was not observed for a long time after irradiation. The results indicate that the smaller the number of radiation induced DSB, the lower the efficiency of their repair. This study was continued on mice by analyzing RIF ( $\mathrm{\gamma H} 2 \mathrm{AX}$ and 53BP1 foci) in various tissues irradiated at doses of 10, $100 \mathrm{mGy}$ and $1 \mathrm{~Gy}$. In the cells of all analyzed tissues of mice exposed to a low dose (10 mGy), but not to a moderate (100 mGy) or a high dose (1 Gy), RIF persisted ( $\gamma \mathrm{H} 2 \mathrm{AX}$ and 53BP1) during 24 hours (Grudzenskia et al., 2010).

It should be noted that at a dose of 10 mGy, DSB were induced not in all cells of the tissue. It is known, that only after whole body irradiation with $10 \mathrm{mGy}$ with low LET (photons or electrons) there may arise about 20 injuries in each cell, on the average, including 0.4-0.5 DSB (NRC, 2006). In fact, at a dose of 10 mGy the DNA of only every second or third cell induces a single DSB (NRC, 2006). On this basis, the authors suggest that the absence of efficient DSB repair after exposure of cells or animals to $10 \mathrm{mGy}$, may be associated with the fact that DSB DNA occur not in all cells being in contact with each other, and the activation of repair occurs not in all cells. This hypothesis assumes that the efficiency of DNA DSB repair in a single cell may be influenced be active repair processes in adjacent cells. That is, the effective repair of DNA DSB in cells is only possible, when all contacting cells contain at least 1 DSB per cell genome, which can occur at doses of 40-80 mGy (Grudzenskia et al., 2010). Such an explanation suggests that the intercellular communication mechanisms or the "bystander effect" play a role in the repair of DNA DSB (Rothkamm and Löbrich, 2003).

In the context of these explanations on the possible role of the "bystander effect", of interest are several publications related to this topic. Thus, it has been shown that irradiation of individual human astrocytes and glioma cells by a microbeam of helium ions generates signals that induce $\gamma \mathrm{H} 2 \mathrm{AX}$ foci in unirradiated neighboring cells, that persist for 48 hours. This bystander effect is not observed in cells mutant in ATR-kinase, but retains on inhibition of their ATM and DNA-PK. In addition, the ATR-dependent induction of the bystander effect, on $\gamma \mathrm{H} 2 \mathrm{AX}$ foci formation, was limited in the S-phase (Belyakov et al., 2005). The recent paper by Ojima et al., (2011) deals with the kinetics of disappearance of RIF (as determined from phosphorylated ATM) in the course of DNA DSB repair in X-rayirradiated human fibroblasts at doses of 1.2, 20, 200 and $1000 \mathrm{mGy}$. It has been shown that the numbers of DSB determined by ATM foci formation $24 \mathrm{~h}$ after irradiation were: $100 \%$ 
(1.2 mGy), 58\% (20 mGy), 12\% (200 mGy) and 8.5\% (1000 mGy) of the original amounts of ATM foci (Ojima et al., 2011). These data are to some extent consistent with the results of studies mentioned above (Rothkamm and Löbrich, 2003; Grudzenskia et al., 2010). However, in studies using the inhibitor of the "bystander effect" (lindane), the authors concluded that the ATM foci detected in the nuclei of cells exposed to low doses (1.2-5 mGy) and persisting in them for a long time after exposure, are mostly related to the bystander effect (Burdak-Rothkamm et al., 2007).

Previously evidence was obtained for an extremely high sensitivity of cells defective in mechanisms for repair of DSB by NHEJ to low doses of radiation (Tomita et al., 2008). The authors have concluded that the process of DNA DSB repair occurring upon low-dose irradiation of cells, is primarily controlled by NHEJ mechanisms, whereas for repairing DSB caused by higher radiation doses, HR is more appropriate (Tomita et al., 2008). Probably, with a small number of DSB the chances that the damaged DNA site and a homologous intact DNA portion in the interphase nucleus will be in close proximity to each other are rather small for a fast start of DSB repair by the HR mechanism.

The data by different authors presented here, though contradictory to some extent, confirm that DDR induced in cells exposed to low-dose radiation differs significantly from that observed under the action of high doses. In the case of low doses or low dose rates, the level of signaling from DNA lesions perceived by transducers is of primary importance for subsequent DDR development, and, above all, for cell cycle checkpoints. Based on studies of the DSB-induced DDR development in yeast, it was assumed that the activation of cell cycle checkpoints occurs as a result of induction of one DNA DSB per cell, and the arrest of the cell cycle will continue until the completion of repair of these injuries. However, studies on mammalian cells have shown that IR doses that cause less than 10-20 DSB/per cell do not contribute to arresting the phase transition G2/M by checkpoints, and this greatly reduces the efficiency of DSB repair (Deckbar et al., 2007; Grudzenskia et al., 2010). On higher doses of ionizing radiation, which induce more than 20 DNA DSB per cell, the checkpoints are activated and arrest the cell cycle phase transition G2/M. But this arrest may not persist until completion of DNA DSB repair (Deckbar et al., 2007; Jeggo, 2009). These results indicate that in the absence of cell cycle arrest, mammalian cells are unable to provide complete repair of DSB induced even at low IR doses. The lack of G2/M transition arrest by the checkpoint until completion of DNA DSB repair leads to rearrangements of chromosomes and their unequal distribution between the two daughter cells.

Obviously, checkpoints must operate efficiently enough to stop the cell cycle progression, and to prevent the transition of cells with DNA DSB to mitosis (Shibata et al., 2010; Warmerdam and Kanaar, 2010). Thus, when DSB in DNA are small in number, the cell cycle checkpoint fails, and mammalian cells in the G2 phase enter mitosis with DNA lesions (Deckbar et al., 2007). Note that similar results were obtained after UV irradiation of yeast cells. The cells did not stop at the G2/M boundary after exposure to low UV light doses, whereas high doses might cause a delay in the cell cycle at the G2/M transition (Callegari and Kelly, 2007).

With a small amount of DSB in DNA, transducer proteins do not sense the signals of damage, so the cell cycle checkpoint is not activated. This situation is confirmed by studies of Collis and colleagues (Collis et al., 2004), which showed that if the alarm signal is weak, that is the amount of critical DNA lesions is small, the transducer proteins did not perceive it, and are not activated by phosphorylation. In the study of these authors several lines of normal and tumor human cells were irradiated by gamma rays at two dose rates. In the first 
case, the dose rate was $9.4 \mathrm{cGy} / \mathrm{h}(\sim 4-5 \mathrm{DSB} / \mathrm{h})$, the second dose rate was $\sim 4500 \mathrm{cGy} / \mathrm{h}(\sim$ $1800 \mathrm{DSB} / \mathrm{h})$. The activation of ATM kinase in response to DNA damage and the formation of $\gamma \mathrm{H} 2 \mathrm{AX}$ foci in cells exposed to low dose rate were shown to be significantly lower than those in cells irradiated with an equivalent dose, but at a high dose rate. This lack of signaling of DNA damage was associated with an increase in cell death after exposure to low intensity radiation. Thus, after exposure to low intensity radiation cells died due to lack of a developed DDR, because at that point the level of damage was not sufficient for its full development. The "molecular radar", (ATM/ATR), able to recognize the DNA DSB did not catch a weak signal from sensor proteins, because the damage was small $(\sim 4-5$ DSB $\mathrm{DNA} / \mathrm{h}$ ) during prolonged exposure (Collis et al., 2004). These results, to some extent, are in agreement with studies by Ishizaki et al.(2004) who showed that after exposure to IR in an acute dose, human cells accumulated a significant amount of $\gamma \mathrm{H} 2 \mathrm{AX}$ foci. However, after chronic exposure of the same line cells to an equivalent dose of radiation there was only a small amount of $\gamma \mathrm{H} 2 \mathrm{AX}$ foci, indicating a low level of DDR in these cells (Ishizaki et al., 2004). The lack of signals of damage and hence of activation of cell cycle checkpoints reduces the efficiency of DSB repair, which contributes to cell death. This event seems to be of vital importance for multicellular organisms because it prevents genetic and carcinogenic consequences.

Previously, evidence was obtained suggesting that the increase in cell death at low DNA damage and low repair efficiency, is a pathway by which cells prevent the transmission of potentially promutagenous DNA damage to the offspring (Joiner et al., 2001). Analysis of cell survival reveals an increased radiosensitivity (to judge from the decay of the initial curve segment) of a particular fraction of cell population at doses of 0.02-0.3 Gy (Joiner et al., 2001; Marples et al., 2004). This phenomenon has come to be known as hyperradiosensitivity of cells. Now it has been determined that hyper-radiosensitivity is associated with failures in the ATM-dependent stage of DDR development and is due to the low efficiency of repair of DSB induced in DNA by low IR doses of both low- and high LET (Wykes et al., 2006; Xue et al., 2009). It was established a direct relation between low-dose hyper-radiosensitivity and the lack of ATM-dependent "early" activation of cell cycle checkpoint at the G2/M transition (Marples et al., 2004). This "early" activation is necessary to prevent the transition of cells irradiated in the G2 phase to mitosis without completion of DNA repair (Marples et al., 2004). It has been shown that an increase in the share of cells at the G2 phase in the overall population, leads to an increase in hyper-radiosensitivity, as most of the damaged cells escape the early delay of G2/M transition thus entering mitosis with non-repaired DSB. In addition, the absence of cell cycle arrest at G2/M transitions, as a result of inhibition of kinases Chk1, Chk2, also leads to an increase in hyper-radiosensitivity (Krueger et al., 2010).

In a recent study it has been found that after exposure of cells to IR, there occurs a dosedependent induction of molecular arrest at G2/M transition (Fernet et al., 2010). Cells irradiated with small doses (about $0.2 \mathrm{~Gy}$ ) at G1 or S phase further progress through the cell cycle, but they are less accumulated in the G2 phase. A block of the G2/M transition for a large number of cells was detected only after their irradiation at higher doses (above $0.5 \mathrm{~Gy}$ ). And the absence of early cell cycle arrest at the G2/M transition by checkpoint control mechanisms correlates with hyper-radiosensitivity of these cells (Fernet et al., 2010). Thus, the increased sensitivity of cells to low IR doses is associated with low levels of DDR due to a small number of critical DNA lesions necessary for the activation of G2 checkpoints, i.e. the cell cycle transitions continue in the presence of critical DNA damage (Marples et al., 
2004; Krueger et al., 2007). As noted above, a possible threshold for full induction of DDR (with activation the checkpoint arrest of cell cycle) in human cells can be 10 to 20 DSB DNA/per cell (Rothkamm and Löbrich, 2003).

\subsection{Limited repair of complex DNA lesions in compacted chromatin}

In eukaryotic cells, the whole cascade of events of DDR development, including recognition of DNA damage, signaling, transduction with activation of the checkpoints, and the repair occur in the chromatin. It is well known that chromatin is a highly compact and dynamic structure in which DNA is packaged with histones and nonhistone proteins. The rigid compaction of chromatin creates a barrier to restrict access to damaged DNA sites for various enzymes and factors (Tang and Greenberg, 2010; Costes et al., 2010). In the case of complex DNA lesions, however, local changes in chromatin structure occur during their repair. The development of DDR is associated with active movement of many proteins to damaged DNA sites within chromatin (Pandita and Richardson, 2009). It is probably because of this DDR-related processes are accompanied with structural reorganization of chromatin and with relaxation of its individual parts. The mechanisms of alterations of local chromatin areas related to appearance of DSB or ICL in DNA are still not clearly understood.

Many studies have shown that modification of chromatin proteins by phosphorylation, methylation, acetylation, ubiquitination, sumoylation and poly ADP-ribosylation plays a critical role not only in the regulation of many genetic processes, but also in DDR development (Pandita and Richardson, 2009; Huertas et al., 2009). Decondensation of chromatin near the region of DNA DSB is considered an important trigger for ATM-dimer dissociation and subsequent autophosphorylation of ATM kinase (Goodarzi et al., 2009).

The results of studies suggest that chromatin at damage sites may be quite structurally dynamic during the repair process, with transient intervals of 'closed' configurations before a more 'open' arrangement that allows the repair machinery to access damaged DNA (Ball \& Yokomori, 2011). DNA damage, in particular DSBs promote to the formation of open, relaxed chromatin regions. These relaxed chromatin structures are created through the coupled action of the p400 SWI/SNF ATPase and histone acetylation by the Tip60 acetyltransferase. The resulting destabilization of nucleosomes at the DSB by Tip60 and p400 is required for ubiquitination of the chromatin by the RNF8 ubiquitin ligase, and for the subsequent recruitment of the BRCA1 and others proteins (Xu \& Price, 2011).

Chromatin dynamics at DSBs can therefore exert a powerful influence on the process of DSB repair. Further, there is emerging evidence that the different chromatin structures in the cell, such as heterochromatin and euchromatin, utilize distinct remodeling complexes and pathways to facilitate DSB. The processing and repair of DSB is therefore critically influenced by the nuclear architecture in which the lesion arises (Xu \& Price, 2011; Ball \& Yokomori, 2011).

Phosphorylation of histone H2AX and other proteins by ATM, ATR and DNA-PKcs near DSB also modifies chromatin, which is crucial in the interactions between many proteins after exposure to IR and, above all, for the process of DNA repair. Thus, chromatin protein modifications contribute to active regulation of multiple reactions associated with the development of whole DDR (Goodarzi et al., 2009; Huertas et al., 2009; Costes et al., 2010).

As a rule, RIF related to chromatin sites with damaged DNA in the cell nuclei are formed not immediately after irradiation. The RIF frequency reaches its maximum (40 RIF/nucleus/Gy) about 15-30 minutes after the action of IR with low LET. Obviously, this is 
the time required for recruitment of proteins that form RIF to the portion of damaged DNA in the chromatin.

Costes and colleagues believe that the long-term persistence RIF (recorded by proteins $\gamma \mathrm{H} 2 \mathrm{AX}, \mathrm{ATM}, 53 \mathrm{BP} 1)$ in the nuclei of irradiated cells is associated with constant rearrangements of chromatin architecture (Costes et al., 2010). On the other hand, the longterm persistent of RIF in compacted sites of chromatin, following exposure of cells to IR suggests that the kinetics of repair of complex DNA lesions is affected by the slow reconstruction of the chromatin, as a result of a "delayed" signal from DNA damage to DDR proteins (Aten et al., 2004; Costes et al., 2010). In addition, the time of formation of RIF and their long-term persistence may depend not only on the original hard compaction of chromatin and cell cycle phase (Goodarzi et al., 2009), but also on the amount of lesions, such as DSB or ICL, as well as single lesions contributing to the relaxation of chromatin (Ploskonosova et al., 1999; Duan and Smerdon, 2010). Thus, a comparison of times of DNA damage persistence in peripheral blood cells of mice irradiated with X-rays at doses of 0.1 and $1 \mathrm{~Gy}$, has shown that in mice irradiated at a dose of $0.1 \mathrm{~Gy}$, the DNA lesions remained for a long time, whereas similar DNA lesions disappeared much faster in mice irradiated at a dose of 1 Gy (Giovanetti et al., 2008).

This difference is to some extent depending on the degree of chromatin relaxation. Another example the results obtained in studying (by RIF's analysis) the repair of DNA DSB induced by low-dose radiation (Grudzenskia et al., 2010). It was shown that primary human fibroblasts are unable for a long time to repair DNA DSB induced by a dose of $10 \mathrm{mGy}$. However, they were able to effectively restore these breaks, if the cells were preliminarily treated with $10 \mu \mathrm{M} \mathrm{H}_{2} \mathrm{O}_{2}$ prior to irradiation. At this $\mathrm{H}_{2} \mathrm{O}_{2}$ concentration, no DSB arise in DNA, and only SSB and base modifications are formed (Grudzenskia et al., 2010). It is believed that additional single DNA lesions cause relaxation areas of chromatin and thus facilitate the process of DNA DSB repair in cells irradiated at a dose of $10 \mathrm{mGy}$.

DNA in heterochromatin and euchromatin may differ both in sensitivity to damaging agents and in the kinetics of damage repair. In compacted heterochromatin DNA is more protected from damaging agents. However, when there is damage, the compaction of heterochromatin restricts the access of repair enzymes to DNA damage (Cowell et al., 2007; Karagiannis et al., 2007; Goodarzi et al., 2008; 2009; 2010). Therefore, the kinetics of RIF appearance and disappearance are heterogeneous in the regions of nuclei of irradiated cells and are significantly different in the heterochromatin and euchromatin. It was found that after irradiation of cells with X-rays, preferential phosphorylation of H2AX histones occurred in the euchromatic areas of nuclei (Goodarzi et al., 2009; 2010). In the heterochromatin, RIF are formed slowly and persist much longer. This characterizes retardation of recognition and repair of DNA damage associated with RIF formation. Recent studies have shown that DNA segments with DSB may move to the periphery of heterochromatin in irradiated human and mouse cells (Jakob et al., 2011). Thus, it is believed that retention of RIF in the nucleus of irradiated cells for a long time is due to a delayed development of DDR and the presence of restrictions on the repair of complex DNA damage (Muniandy et al., 2010; Belyaev, 2010; Goodarzi et al., 2010).

ATM, as noted above, is a key unit of signaling in the development of DDR, and contributes to changes in the structure of chromatin in the vicinity of DSB and to the activation of repair of this damage. It is well known that the majority of DSB (85\%) can be repaired with faster kinetics, mainly by an ATM-independent pathway. The repair of the other part of IRinduced DSB (15\%) occurs by the slow kinetics, and this process requires involvement of 
ATM and mediator proteins such as MDC1 and 53BP1, which are accumulated in RIF. Slowly repaired DSB are predominantly localized in DNA within heterochromatin (Cowell et al., 2007;). Further investigations showed that the heterochromatic superstructure creates a barrier to the functioning of ATM in the development of DDR and DNA DSB repair (Goodarzi et al., 2009; Jakob et al., 2011). However, although slowly, the DSB repair of DNA within heterochromatin does occur. The repair of DNA in heterochromatin requires relaxation of its structure. This relaxation is achieved by various modifications of chromatin proteins, in particular, by ATM-kinase phosphorylation of heterochromatin proteins (Noon et al., 2010; Cann and Dellaire 2011). An important role in this process belongs to the protein KAP-1 (a protein known as TIF1beta, TRIM28), which undergoes phosphorylation by ATM. Protein KAP-1 is a critical factor that contributes to repair of DSB DNA in the heterochromatin package. Phosphorylated KAP-1 (pKAP-1) is found in RIF at heterochromatin sites and promotes DSB repair and the mitotic progression (Noon et al., 2010).

Thus, the critical lesions of DNA in the heterochromatin packing persist for a long postirradiation time, due to the necessity of its "opening" to make damaged DNA sites easily accessible for repair system components. At low IR doses, heterochromatin relaxes to a less extent, so that the access of repair enzymes to DNA damage is limited.

It is precisely this situation that arises in DNA damage in post meiotic male germ cells - the spermatozoa. This is because male germ cells gradually, from stage to stage, lose their ability to effectively repair complex DNA lesions during spermatogenesis. The causative factor in the low activity of DNA repair systems in spermatozoa is the rigid package of the haploid genome, created by protamines in these cells. Haploid male germ cells pack their DNA in a volume of less than $10 \%$ of a somatic cell nucleus. To achieve this level of DNA compaction, sperm cells have replaced most of their histones by protamines (Oliva, 2006; Marchetti et al., 2007).

So in the male germ cells DDR development is very slow, and formed RIF ( $\gamma \mathrm{H} 2 \mathrm{AX})$ are stored for longer periods of time than those in somatic cells (Paris et al., 2011). Studies in mice show that many radiation-induced DNA lesions in mature spermatozoa are not subject to repair and persist for at least 7 days (Marchetti and Wyrobek, 2008; Ahmed et al., 2010). However, male gametes with DNA damage are able to fertilize oocytes. DNA repair in the spermatozoon occurs, to a large extent, after their penetration into the ovum, the repair systems of the latter being involved in the process. Prior to DNA repair, reconstruction of chromatin is, obviously, required, accompanied by substitution of oocyte histones for protamines (Marchetti and Wyrobek, 2008; Ahmed et al., 2010; Paris et al., 2011).

\section{Conclusion}

In recent years our understandings of the effects of low doses of ionizing radiation on organisms, as well as features of the formation of DNA damage and repair have increased significantly. Based on data from many studies, we conclude that the majority of lesions occurring in the DNA of IR-exposed cells differ significantly in their chemical nature from the endogenous damage. The most important characteristics of radiation-induced DNA damage are their complexity and clustering. DSB, ICL or destruction of the replication fork and formation of long single-stranded gaps in DNA are considered as critical for the fate of damaged cells. The occurrence of such lesions in DNA may be a key event in both the etiology and the treatment of cancer. A complex radiation-induced DNA lesion is a serious burden for constitutive cellular repair systems. 
In contrast to endogenous damage, repair of radiation-induced damage is accompanied by significant errors. With appearance of critical lesions in DNA, the cells rapidly develop a complex branched network of molecular and biochemical reactions, which are known as DNA damage response (DDR). Induction of DDR is associated with activation of cell cycle checkpoints, DNA repair, changes in the expression of many genes, chromatin reconstruction or apoptosis. However, the efficiency of repair of complex DNA lesions in cells exposed to low-dose radiation remains at low levels. The development of cell response to DNA damage at low radiation doses does not reach of the desired result, due to a small amount of damage, so that the progression of the cell cycle through the phases is ahead of DNA repair processes. This is primarily due to the failure of signaling from critical DNA lesions (low damage at low doses of radiation) to activation checkpoint to the cell cycle arrest. In the absence of cell cycle arrest, especially in the G2/M transition, the repair systems do not have time to complete DNA recovery, so that the cells enter mitosis with damaged DNA.

On the other hand, since eukaryotic chromosomal DNA is packaged into chromatin, there is evidence that the modulation of chromatin structure is crucial for the development of the DDR checkpoint signaling and repair. The compaction of DNA within chromatin, and most of all in the heterochromatin, poses a unique hindrance with regards to the accessibility of the DNA to enzymes involved in repair.

Therefore, another cause of the low efficiency of DNA repair in cells exposed to low radiation doses may be a slow reconstruction of chromatin and limited access of repair system components to complex lesions of DNA packed in compacted chromatin.

Now become clear that the responses of higher eukaryotes cells to low doses of radiation are different from those induced by high doses, not only quantitatively but qualitatively. Further research is needed on many aspects to this problem.

\section{Acknowledgments}

The author would like to thank Margaret Ilina for her excellent help in the preparation of this manuscript. This work was supported by the Basic Sciences to Medicine program of the Presidium of the Russian Academy of Sciences and the Russian Foundation for Basic Research (Grant 08-04-00163).

\section{References}

Ahmed, E.A., de Boer, P., Philippens. M.E., Kal, H.B. \& de Rooij, D.G. (2010). Parp1-XRCC1 and the repair of DNA double strand breaks in mouse round spermatids. Mutat. Res., 683 (1-2), 84-90.

Allen, C., Ashley, A.K., Hromas, R. \& Nickoloff J.A. (2011). More forks on the road to replication stress recovery. J. Mol.Cell Biol., 3, (1) 4-12, doi:10.1093/jmcb/mjq049

Alter, B.P. (2002). Radiosensitivity in Fanconi's anemia patients. Radiother. Oncol., 62 (3), 345-347.

Asaithamby, A., Hu, B., \& Chen, D.J. (2011). Unrepaired clustered DNA lesions induce chromosome breakage in humancells. Proc. Natl. Acad. Sci. USA, 108 (20), 8293-8298.

Aten, J.A., Stap, J., Krawczyk, P.M., van Oven, C.H., Hoebe, R.A., Essers, J. \& Kanaar, R., (2004). Dynamics of DNA double-strand breaks revealed by clustering of damaged chromosome domains. Science, 303 (5654), 92-95. 
Averbeck, D. (2009). Does scientific evidence support a change from the LNT model for lowdose radiation risk extrapolation? Health Phys., 97 (5), 493-504.

Ball, A.R. Jr. \& Yokomori, K. (2011). Damage site chromatin: open or closed? Curr. Opin. Cell Biol., 23 (3), 277-283.

Barnes, D.E., \& Lindahl, T. (2004) Repair and genetic consequences of endogenous DNA base damage in mammalian cells. Annu. Rev. Genet., 38, 445-476.

Bartek, J. \& Lukas,J. (2007). DNA damage checkpoints: from initiation to recovery or adaptation. Curr. Opinion Cell Biol., 19 (2), 238-245.

Bartek, J., Bartkova, J., \& Lukas, J. (2007). DNA damage signalling guards against activated oncogenes and tumour progression. Oncogene, 26 (56), 7773-7779.

Belyaev, I.Y. (2010). Radiation-induced DNA repair foci: Spatio-temporal aspects of formation,application for assessment of radiosensitivity and biological dosimetry. Mutat. Res., 704 (1-3), 132-141.

Belyakov, O.V., Mitchell, S.A., Parikh, D., Randers-Pehrson, G., Marino, S., Amundson, S.A., Geard, C.R. \& Brenner, D.J. (2005). Biological effects in unirradiated human tissue induced by radiation damage up to $1 \mathrm{~mm}$ away. Proc. Natl. Acad. Sci. USA, 102 (40), 14203-14208.

Bennett, P.V., Cintron, N.S., Gros, L., Laval, J. \& Sutherland, B.M. (2004). Are endogenous clustered DNA damages induced in human cells? Free Radic. Biol. Med., 37 (4), 488-499.

Ben-Yehoyada, M., Wang, L.C., Kozekov, I.D., Rizzo, C.J., Gottesman, M.E. \& Gautier, J. (2009). Checkpoint signaling from a single DNA interstrand crosslink. Mol. Cell., 35 (5), 704-715.

Bernstein, N.K., Karimi-Busheri, F., Rasouli-Nia, A., Mani, R., Dianov, G., Glover, J.N. \& Weinfeld, M. (2008). Polynucleotide kinase as a potential target for enhancing cytotoxicity by ionizing radiation and topoisomerase I inhibitors. Anticancer Agents Med. Chem., 8 (4), 358-367

Bont, R.D. \& van Larebeke, N. (2004). Endogenous DNA damage in humans: a review of quantitative data. Mutagenesis, 19 (3), 169-185.

Borde, V, \& Cobb, J. (2009). Double functions for the Mre11 complex during DNA doublestrand break repair and replication. Int. J. Biochem. Cell Biol., 41 (6), 1249-1253.

Brenner, D.J., Doll, R., Goodhead, D.T., Hall, E.J., Land, C.E., Little, J.B., Lubin, J.H., Preston, D.L., Preston, R.J., Puskin, J.S., Ron, E., Sachs, R.K., Samet, J.M., Setlow, R.B., \& Zaider, M. (2003). Cancer risk attributable to low doses of ionizing radiation: assessing what we really know. Proc Natl Acad Sci USA, 100 (24), 13761-13766.

Burdak-Rothkamm, S., Short, S., Folkard, M., Rothkamm, K. \& Prise, K.M. (2007). ATRdependent radiation-induced gamma H2AX foci in bystander primary human astrocytes and glioma cells. Oncogene, 26 (7), 993-1002.

Callegari, A.J. \& Kelly T.J. (2007). Shedding light on the DNA damage checkpoint. Cell Cycle, $6(6), 660-666$.

Callegari, A.J., Clark, E., Pneuman, A., \& Kelly T.J. (2010). Postreplication gaps at UV lesions are signals for checkpoint activation. Proc. Natl. Acad. Sci. U S A, 107 (18), 8219-8224.

Cann, K.L. \& Dellaire, G. (2011). Heterochromatin and the DNA damage response: the need to relax. Biochem. Cell Biol., 89 (1), 45-60.

Cejka, P., Cannavo, E., Polaczek, P., Masuda-Sasa, T., Pokharel, S., Campbell, J. \& Kowalczykowski, S. C. (2010). DNA end resection by Dna2-Sgs1-RPA and its stimulation by Top3-Rmi1 and Mre11-Rad50-Xrs2. Nature, 467 (7311), 112-116. 
Celeste, A., Petersen, S., Romanienko, P.J., Fernandez-Capetillo, O., Chen, H.T., Sedelnikova, O.A., Reina-San-Martin, B.,

Coppola, V., Meffre, E., Difilippantonio, M.J., Redon, C., Pilch, D.R., Olaru, A., Eckhaus, M., Camerini-Otero, R.D., Tessarollo, L., Livak, F., Manova, K., Bonner, W.M., Nussenzweig, M.C. \& Nussenzweig, A. (2002). Genomic instability in mice lacking histone H2AX. Science, 296 (5569), 922-927.

Chung, J. \& Bunz, F. (2010). Cdk2 is required for p53 independent G2/M checkpoint control. PLoS Genet., 6 (2), e1000863.

Cimprich, K. \& Cortez, D. (2008). ATR: an essential regulator of genome integrity, Nat. Rev. Mol. Cell Biol., 9 (8), 616-627.

Cole, A.R., Lewis, L.P. \& Walden, H. (2010). The structure of the catalytic subunit FANCL of the Fanconi anemia core complex. Nat. Struct. Mol. Biol., 17 (3), 294-298.

Collis, S.J., Schwaninger, J., Ntambi, A., Keller, T.W., Nelson, W.G., Dillehay, L.E. \& DeWeese, T.L. (2004). Evasion of

Early Cellular Response Mechanisms following Low Level Radiation-induced DNA Damage. J. Biol. Chem., 279 (48), 49624-49632.

Cook, J.G. (2009). Replication licensing and the DNA damage checkpoint. Front Biosci., 14, 5013-5030.

Costantini, S.,Woodbine, L., Andreoli, L., Jeggo, P.A. \& Vindigni, A. (2007). Interaction of the $\mathrm{Ku}$ heterodimer with the DNA ligase IV/Xrcc4 complex and its regulation by DNA-PK. DNA Repair(Amst), 6 (6), 712-722

Costes, S.V., Boissiere, A., Ravani, S., Romano, R., Parvin, B. \& Barcellos-Hoff, M.H. (2006). Imaging features that discriminate between foci induced by high- and low-LET radiation in human fibroblasts. Radiat. Res., 165 (5), 505-515.

Costes, S.V., Chiolo, I., Pluth, J.M., Barcellos-Hoff, M.H. \& Jakob, B. (2010). Spatiotemporal characterization of ionizing radiation induced DNA damage foci and their relation to chromatin organization. Mutat. Res., 704 (1-3), 78-87.

Cowell, I.G., Sunter, N.J., Singh, P.B., Austin, C.A., Durkacz, B.W., Tilby, M.J., (2007). Gamma- H2AX foci form preferentially in euchromatin after ionising-radiation, PLoS One, 2 (10), e1057. doi: 10.1371.

Das, P., Bennett, P. \& Sutherland, B.M. (2011). Processing of abasic DNA clusters in hApeIsilenced primary fibroblasts exposed to low doses of X-irradiation. J. Biosci., 36 (1), 105-116.

Deckbar, D., Birraux, J., Krempler, A., Tchouandong, L., Beucher, A., Walker, S., Stiff, T., Jeggo, P.A. \& Löbrich, M. (2007). Chromosome breakage after G2 checkpoint release. J. Cell Biol., 176 (6), 748-755.

Dextraze, M.E., Gantchev, T., Girouard, S. \& Hunting, D. (2010). DNA interstrand crosslinks induced by ionizing radiation: An unsung lesion. Mutat. Res., 704 (1-3), 101107.

Dianov, G.L., O'Neill, P. \& Goodhead, D.T. (2001). Securing genome stability by orchestrating DNA repair: removal of radiation-induced clustered lesions in DNA. Bioessays, 23 (8), 745-749

Ding, H. \& Greenberg, M.M., (2007). Gamma-radiolysis and hydroxyl radical produce interstrand cross-links in DNA involving thymidine. Chem. Res. Toxicol., 20 (11), 1623-1628.

Ding, L.H., Shingyoji, M., Chen, F., Hwang, J.J., Burma, S., Lee, C., Cheng, J.F. \& Chen, D.J. (2005). Gene expression profiles of normal human fibroblasts after exposure to 
ionizing radiation: a comparative study of low and high doses. Radiat. Res., 164 (1), 17-26.

Duan, M. \& Smerdon, M.J. (2010). UV damage in DNA promotes nucleosome unwrapping. J. Biol. Chem., 285 (34), 26295-26303.

Eccles, L.J., Lomax, M.E., O'Neill, P. (2010). Hierarchy of lesion processing governs the repair, double-strand break formation and mutability of three-lesion clustered DNA damage. Nucleic Acids Res., 38 (4), 1123-1134

Falck, J., Coates, J. \& Jackson S.P. (2005). Conserved modes of recruitment of ATM, ATR and DNA-PKcs to sites of DNA damage. Nature, 434 (7033), 605-611.

Fernet, M., Mégnin-Chanet, F., Hall, J. \& Favaudon,V. (2010). Control of the G2/M checkpoints after exposure to low doses of ionising radiation: implications for hyper-radiosensitivity. DNA Repair (Amst), 9 (1), 48-57.

Freeman, A.K. \& (Monteiro, A.N. (2010). Phosphatases in the cellular response to DNA Damage. Cell Commun. Signal., 8 (27), doi: 10.1186-8-27

Gantchev, T.G., Girouard, S., Dodd, D.W., Wojciechowski, F., Hudson, R.H. \& Hunting, D.J. (2009). Gamma-radiation induced interstrand cross-links in PNA:DNA heteroduplexes. Biochemistry, 48 (29), 7032-7044.

Gaziev, A.I. (1999). DNA damage in cells exposed to ionizing radiation. Radiat. Biol. Radioecol., 39 (5), 630-639.

Ghandhi, S., Sinha, A., Markatou, M. \& Amundson, S. (2011). Time-series clustering of gene expression in irradiated and Bystander fibroblasts: an application of FBPA clustering. BMC Genomics, 12 (2), 121-133.

Giovanetti, A., Deshpande, T. \& Basso, E. (2008). Persistence of genetic damage in mice exposed to low dose of $\mathrm{X}$ rays. Int. J. Radiat. Biol., 84 (3), 227-235.

Goldberg, M., Stucki, M., Falck, J., D’Amours, D., Rahman, D., Pappin, D.,Bartek J. \& Jackson, S.P. (2003). MDC1 is = required for the intra-S-phase DNA damage checkpoint. Nature, 421 (6926), 952-956.

Goodarzi, A., Noon, A., Deckbar, D., Ziv, Y., Shiloh, Y., Löbrich, M. \& Jeggo, P.A. (2008) ATM signaling facilitates repair of DNA double-strand breaks associated with heterochromatin. Mol. Cell., 31 (2), 167-177.

Goodarzi, A.A., Noon, A.T. \& Jeggo, P.A. (2009). The impact of heterochromatin on DSB repair. Biochem. Soc. Trans. 37 (Pt.3), 569-576.

Goodarzi, A.A., Jeggo, P. \& Löbrich, M. (2010). The influence of heterochromatin on DNA double strand break repair:

Getting the strong, silent type to relax. DNA Repair (Amst), 9 (12), 1273-1282.

Grillari, J., Katinger, H. \& Voglaue, R. (2007). Contributions of DNA interstrand cross-links to aging of cells and organisms. Nucleic Acids Res., 35 (22), 7566-7576

Grudzenskia, S., Rathsa, A., Conrada, S., Rubeb, C.E. \& Löbrich, M. (2010). Inducible response required for repair of low-dose radiation damage in human fibroblasts. Proc. Natl. Acad. Sci. USA, 107 (32), 14205-14210.

Gu, J., Lu, H.,Tsai, A.G., Schwarz, K. \& Lieber, M.R. (2007). Single-stranded DNA ligation and XLF-stimulated incompatible DNA end ligation by the XRCC4-DNA ligase IV complex: influence of terminal DNA sequence. Nucleic Acids Res., 35 (17), 5755-5762.

Gulston, M., de Lara, C., Jenner, T., Davis, E. \& O'Neill, P. (2004). Processing of clustered DNA damage generates additional double-strand breaks in mammalian cells postirradiation. Nucleic Acids Res., 32 (41), 602-1609.

Haber, J.E. (2008). Alternative endings. Proc. Natl. Acad. Sci. USA, 105 (2), 405-406. 
Hada M. \& Georgakilas A.G. (2008). Formation o cluster DNA damage after high LET irradiation: A review. J. Radiat. Res., 49 (3), 203-210.

Halazonetis, T.D., Gorgoulis, V.G. \& Bartek, J. (2008). An oncogene-induced DNA damage model for cancer development. Science, 319 (5868), 1352-1355.

Harper, J.W. \& Elledge, S.J. (2007). The DNA damage response: ten years after. Mol. Cell., 28 (5), 739-745.

Harrison, J.C. \& Haber, J.E. (2006). Surviving the breakup: The DNA damage checkpoint. Annu. Rev. Genet., 40, 209-235.

Hayes D.P. (2008). Non-problematic risks from low-dose radiation-induced DNA damage clusters. Dose-Response, 6 (1), 30-52.

Heyer, W.D., Ehmsen, K.T. \& Liu, J. (2010). Regulation of homologous recombination in eukaryotes. Annu. Rev. Genet., 44, 113-139.

Heilmann, J., Rink, H., Taucher-Scholz, G. \& Kraft, G. (1993). DNA strand break induction and rejoining and cellular recovery in mammalian cells after heavy-ion irradiation. Radiat. Res., 135 (1), 46-55.

Hejna, J., Holtorf, M., Hines, J., Mathewson, L., Hemphill, A., Olson, S.B. \& Moses, R.E. (2008). Tip60 is required for DNA interstrand cross-link repair in the Fanconi anemia pathway. J. Biol. Chem., 283 (15), 9844-9851.

Heyer, W.D., Ehmsen, K.T. \& Liu, J. (2010). Regulation of homologous recombination in eukaryotes. Annu. Rev. Genet., 44, 113-139.

Hildebrandt, G. (2010). Non-cancer diseases and non-targeted effects. Mutat. Res., 687 (1-2), 73-77.

Hinz, J.M. (2010). Role of homologous recombination in DNA interstrand crosslink repair. Environ. Mol. Mutagen., 51 (6), 582-603.

Ho, T.V. \& Schärer, O.D. (2010). Translesion DNA synthesis polymerases in DNA interstrand crosslink repair. Environ. Mol. Mutagen., 51 (6), 552-566.

Hoeijmakers, J.H. (2001). Genome maintenance mechanisms for preventing cancer. Nature, 411 (6835), 366-374.

Hong, H., Cao, H. \& Wang, Y. (2007). Formation and genotoxicity of a guanine-cytosine intrastrand cross-link lesion in vivo. Nucleic Acids Res., 35 (21), 7118-7127.

$\mathrm{Hu}, \mathrm{H}$. \& Gatti R.A. (2011). MicroRNAs: new players in the DNA damage response. J. Mol. Cell Biol., 3 (3), 151-158.

Huang, X., Okafuji, M., Traganos, F., Luther, E., Holden, E. \& Darzynkiewicz, Z. (2004). Assessment of histone H2AX phosphorylation induced by DNA topoisomerase I and II inhibitors topotecan and mitoxantrone and by the DNA cross-linking agent cisplatin. Cytometry A, 58 (2), 99-110.

Huertas, P. (2010). DNA resection in eukaryotes: deciding how to fix the break. Nat. Struct. Mol. Biol., 17 (1), 11-16.

Huertas, P., Sendra, R. \& Muñoz, P. (2009). Chromatin dynamics coupled to DNA repair. Epigenetics, 4 (1), 31-42.

Ide, H, Shoulkamy, M.I., Nakano, T., Miyamoto-Matsubara, M. \& Salem, A.M. (2011). Repair and biochemical effects of DNA-protein crosslinks. Mutat. Res., 711 (1-2), 113-122.

Ishizaki, K., Hayashi, Y., Nakamura, H., Yasui, Y., Komatsu, K. \& Tachibana, A. (2004). No induction of p53 phosphorylation and few focus formation of phosphorylated H2AX suggest efficient repair of DNA damage during chronic low-doseirradiation in human cells. J. Radiat. Res., 45 (4), 521-525. 
Jackson, S. \& Bartek, J. (2009). The DNA-damage response in human biology and disease. Nature, 461 (7267), 1071-1078.

Jakob, B., Splinter, J., Conrad, S., Voss, K., Zink, D., Durante, M., Löbrich, M. \& TaucherScholz, G. (2011). DNA double- strand breaks in heterochromatin elicit fast repair protein recruitment, histone $\mathrm{H} 2 \mathrm{AX}$ phosphorylation and relocation to euchromatin. Nucleic Acids Res., doi:10.1093/nar/gkr230.

Jeggo, P.A. (2009). Risks from low dose/dose rate radiation: what an understanding of DNA damage response mechanisms can tell us. Health Phys., 97 (5), 1-10.

Jeggo, P. (2010). The role of the DNA damage response mechanisms after low-dose radiation exposure and a consideration of potentially sensitive individuals. Radiat. Res., 174 (6), 825-832.

Joiner, M.C., Marples, B., Lambin, P., Short, S.C. \& Turesson, I., (2001). Low-dose hypersensitivity: Current status and possible mechanisms. Int. J. Radiat. Oncol. Biol. Phys., 49 (2), 379-389.

Karagiannis, T.C., Harikrishnan, K.N. \& El-Osta, A. (2007). Disparity of histone deacetylase inhibition on repair of radiation-induced DNA damage on euchromatin and constitutive heterochromatin compartments. Oncogene, 26 (27), 3963-3971.

Kastan, M.B. \& Bartek, J. (2004). Cell-cycle checkpoints and cancer. Nature, 432 (7015), 316-23.

Knipscheer, P., Räschle, M., Smogorzewska, A., Enoiu, M., Ho, T.V., Schärer, O.D., Elledge, S.J. \& Walter, J.C. (2009). The Fanconi anemia pathway promotes replicationdependent DNA interstrand crosslink repair. Science, 326 (5960), 1698-1701.

Kolas, N.K., Chapman, J.R., Nakada, S., Ylanko, J., Chahwan, R., Sweeney, F.D., Panier, S., Mendez, M., Wildenhain, J.,

Thomson, T.M., Pelletier, L., Jackson, S.P. \& Durocher, D. (2007). Orchestration of the DNAdamage response by the RNF8 ubiquitin ligase. Science, 318 (5856), 1637-1640.

Krueger, S.A., Collis, S.J., Joiner, M.C., Wilson, G.D. \& Marples, B. (2007). Transition in survival from low dose hyper-radiosensitivity to increased radioresistance is independent of activation of ATM Ser1981 activity. Int. J. Radiat. Oncol. Biol. Phys., 69 (4), 1262-1271.

Krueger, S.A., Wilson, G.D., Piasentin, E., Joiner, M.C. \& Marples, B. (2010). The effects of G2-phase enrichment and checkpoint abrogation on low-dose hyperradiosensitivity. Int. J. Radiat. Oncol. Biol. Phys., 77 (5), 1509-1517.

Kuhnert, V.M., Kachnic, L.A., Li, L., Purschke, M., Gheorghiu, L., Lee, R., Held, K.D. \& Willers, H. (2009). FANCD2-deficient human fibroblasts are hypersensitive to ionizing radiation at oxygen concentrations of $0 \%$ and $3 \%$ but not under normoxic conditions. Int. J. Radiat. Biol., 85 (6), 523-531.

Lassmann, M., Hänscheid, H., Gassen, D., Biko, J., Meineke, V., Reiners, C. \& Scherthan, H. (2010). In vivo formation of gamma-H2AX and 53BP1 DNA repair foci in blood cells after radioiodine therapy of differentiated thyroid cancer. J. Nucl. Med., 51 (8), 1318-1325.

Lavin, M.F., Kozlov, S. (2007). ATM Activation and DNA Damage Response. Cell Cycle, 6 (8), 931-942.

Lee, J.H. \& Paull, T.T. (2007). Activation and regulation of ATM kinase activity in response to DNA double-strand breaks. Oncogene, 26 (56), 7741-7748

Legerski, R.J. (2010). Repair of DNA interstrand cross-links during S phase of the mammalian cell cycle. Environ. Mol. Mutagen., 51 (6), 540-551. 
Lieber, M.R. (2010). The mechanism of double-strand DNA break repair by the nonhomologous DNA end-joining pathway. Annu. Rev. Biochem., 79, 181-211.

Lindahl, T. (1993). Instability and decay of the primary structure of DNA. Nature, 362 (6422), 709-715.

Liu, T., Ghosal, G., Yuan, J., Chen, J. \& Huang, J. (2010). FAN1 acts with FANCI-FANCD2 to promote DNA interstrand cross-link repair. Science, 329 (5992), 693-696

Löbrich, M., Shibata, A., Beucher, A., Fisher, A., Ensminger, M., Goodarzi, A.A., Barton, O. \& Jeggo, P.A. (2010). $\gamma-\mathrm{H} 2 \mathrm{AX}$ foci analysis for monitoring DNA double-strand break repair. Strengths, limitations and optimization. Cell Cycle, 9 (4), 662-669.

Mahaney, B.L., Meek, K. \& Lees-Miller, S.P. (2009). Repair of ionizing radiation-induced DNA double-strand breaks by non-homologous end-joining. Biochem. J., 417 (3), 639-650.

Marchetti, F., Essers, J., Kanaar, R. \& Wyrobek, A.J. (2007). Disruption of maternal DNA repair increases sperm-derived chromosomal aberrations. Proc. Natl. Acad. Sci. USA, 107 (45), 17725-17729.

Marchetti, F. \& Wyrobek, A.J. (2008). DNA repair decline during mouse spermiogenesis results in the accumulation of heritable DNA damage. DNA Repair (Amst), 7 (4), $572-581$.

Marples, B., Wouters, B., Collis, S., Chalmers, A. \& Joiner, M. (2004). Low-dose hyperradiosensitivity: a consequence of ineffective cell cycle arrest of radiation-damaged G2-phase cells. Radiat. Res., 161 (3), 247-255.

Matsuoka, S., Ballif, B., Smogorzewska, A., McDonald, E., Hurov, K.E., Luo, J., Bakalarski, C.E., Zhao, Z., Solimini, N., Lerenthal, Y., Shiloh, Y., Gygi, S.P., \& Elledge, S.J. (2007). ATM and ATR substrate analysis reveals extensive protein networks responsive to DNA damage. Science, 316 (5828), 1160-1166.

McVey, M. \& Lee, S. (2008). MMEJ repair of double-strand breaks (director's cut): deleted sequences and alternative endings. Trends Genet., 24 (11), 529-538.

Mimitou, E.P. \& Symington, L.S. (2008). Sae2, Exo1 and Sgs1 collaborate in DNA double strand break processing. Nature, 455 (7214), 770-774.

Misteli, T. \& Soutoglou, E. (2009). The emerging role of nuclear architecture in DNA repair and genome maintenance. Nat. Rev. Mol. Cell Biol., 10 (4), 243-254

Modesti, M., Budzowska, M., Baldeyron, C., Demmers, J.A., Ghirlando, R., \& Kanaar, R., (2007). RAD51AP1 is a structure-specific DNA binding protein that stimulates joint molecule formation during RAD51-mediated homologous recombination. Mol. Cell, 28 (3), 468-481.

Mogi, S. \& Oh, D.H. (2006). $\gamma-H 2 A X$ formation in response to interstrand crosslinks requires XPF in human cells. DNA Repair (Amst), 5 (6), 731-740.

Mogi, S., Butcher, C.E. \& Oh, D.H. (2008). DNA polymerase $\eta$ reduces the $\gamma$-H2AX response to psoralen interstrand crosslinks in human cells. Exp. Cell Res., 314 (4), 887-895.

Moldovan, G.L. \& D'Andrea, A.D. (2009). How the Fanconi anemia pathway guards the genome. Annu. Rev. Genet., 43, 223-249.

Moon, A.F., Garcia-Diaz, M., Batra, V.K., Beard, W.A., Bebenek, K., Kunkel, T.A., Wilson, S.H. \& Pedersen, L.C. (2007). The $X$ family portrait: structural insights into biological functions of X family polymerases. DNA Repair (Amst), 6 (12), 1709-1725.

Mullenders, L., Atkinson, M., Paretzke, H., Sabatier, L. \& Bouffler, S. (2009). Assessing cancer risks of low-dose radiation. Nat. Rev. Cancer, 9 (8), 596-604. 
Muniandy, P., Liu. J., Majumdar, A., Liu, S. \& Seidman M.M. (2010). DNA interstrand cross links repair in mammalian cells: step by step. Crit. Rev. Biochem. Mol. Biol., 45 (1), 23-49.

Nagy, Z. \& Soutoglou, E. (2009). DNA repair: easy to visualize, difficult to elucidate. Trends Cell Biol., 19 (11), 617-629.

Natarajan, A.T. \& Palitti, F. (2008). DNA repair and chromosomal alterations. Mutat. Res. 657 (1), 3-7.

Nichols, G. J., Schaack, J. \& Ornelles, D. A. (2009). Widespread phosphorylation of histone H2AX by species $C$ adenovirus infection requires viral DNA replication. J. Virol., 83 (12), 5987-5998.

Niedernhofer, L.J.,Daniels, J.S., Rouzer, C.A., Greene, R.E., Marnett, L.J. (2003). Malondialdehyde, a product of lipid peroxidation, is mutagenic in human cells. J. Biol. Chem., 278 (33), 31426-31433.

Niida, H., Murata, K., Shimada, M., Ogawa, K., Ohta, K., Suzuki, K., Fujigaki, H., Khaw, A.K., Banerjee, B., Hande, M.P., Miyamoto, T., Miyoshi, I., Shirai, T., Motoyama, N., Delhase, M., Appella, E. \& Nakanishi, M. (2010). Cooperative functions of Chk1 and Chk2 reduce tumour susceptibility in vivo. EMBO J., 29 (20), 3558-3570.

Noll, D., Mason, T. \& Miller, P.S. (2006). Formation and repair of interstrand cross-links in DNA. Chem. Rev., 106 (2), 277-301.

Noon, A.T., Shibata, A., Rief, N., Löbrich, M., Stewart, G.S., Jeggo, P.A. \& Goodarzi, A.A. (2010). 53BP1-dependent robust localized KAP-1 phosphorylation is essential for heterochromatic DNA double-strand break repair. Nat. Cell. Biol., 12 (2), 177-184.

NRC (National Research Council of the NAS). (2006). Health Risks from Exposure to Low Levels of Ionizing Radiation (BEIR VII, Phase 2). National Academies Press, Washington, DC. pp 30-143.

Ojima, M., Furutani, A., Ban, N. \& Kai, M. (2011). Persistence of DNA double-strand breaks in normal human cells induced by radiation-induced bystander effect. Radiat. Res. 175 (1), 90-96.

Oliva, R. (2006). Protamines and male infertility. Hum. Reproduc. Update, 12 (4), 417-435.

Olive, P.L. \& Banath, J.P. (2009). Kinetics of H2AX Phosphorylation After Exposure to Cisplatin. Cytometry B. Clinic. Cytom. 76 (2), 79-90.

Pandita, T.K. \& Richardson, C. (2009). Chromatin remodeling finds its place in the DNA double-strand break response. Nucleic Acids Res., 37 (5), 1363-1377.

Pardo, B., Gomez-Gonzalez, B. \& Aguilera, A. (2009). DNA double-strand break repair: how to fix a broken relationship. Cell. Mol. Life Sci., 66 (6), 1039-1056.

Paris, L., Cordelli, E., Eleuteri, P., Grollino, M.G., Pasquali, E., Ranaldi, R., Meschini, R. \& Pacchierotti, F. (2011). Kinetics of g-H2AX induction and removal in bone marrow and testicular cells of mice after X-ray irradiation. Mutagenesis, 26 (4), 563-572.

Parrilla-Castellar, E.R., Arlander, S.J. \& Karnitz, L. (2004). Dial 9-1-1 for DNA damage: the Rad9-Hus1-Rad1 (9-1-1) clamp complex. DNA Repair (Amst), 3 (8-9), 1009-1014.

Ploskonosova, I.I., Baranov, V.I. \& Gaziev, A.I. (1999). PCR assay of DNA damage and repair at the gene level in brain and spleen of gamma-irradiated young and old rats. Mutat. Res., 434 (2), 109-117.

Pebg, X., Ghosh, A.K., Van Houten, B., \& Greenberg, M.M. (2010). Nucleotide excision repair of a DNA interstrand cross-link produces single- and double-strand breaks. Biochemistry, 49 (1), 11-19. 
Radulescu, I., Elmroth, K. \& Stenerlöw, B. (2004). Chromatin organization contributes to non-randomly distributed double-strand breaks after exposure to high-LET radiation. Radiat. Res., 161 (1), 1-8.

Rass, U., Ahel, I. \& West, S.C. (2008). Molecular mechanism of DNA deadenylation by the neurological disease protein aprataxin. J. Biol. Chem., 283 (49), 3394-4001.

Redon, C.E., Nakamura, A.J., Sordet, O., Dickey, J.S., Gouliaeva, K., Tabb, B., Lawrence, S., Kinders, R.J., Bonner, W.M.,

Sedelnikova, O.A. (2011). $\mathrm{\gamma}$-H2AX Detection in peripheral blood lymphocytes, splenocytes, bone marrow, xenografts, and skin. Methods Mol. Biol., 682, 249-270.

Regulus, P., Duroux, B., Bayle, P. A., Favier, A., Cadet, J. \& Ravanat, J. L. (2007). Oxidation of the sugar moiety of DNA by ionizing radiation or bleomycin could induce the formation of a cluster DNA lesion. Proc. Natl. Acad. Sci. USA, 104 (35), 14032-14037.

Rogakou, E.P., Boon, C., Redon, C. \& Bonner, W.M. (1999). Megabase chromatin domains involved in DNA double-strand breaks in vivo. J. Cell Biol., 146 (5), 905-916.

Rothkamm, K. \& Löbrich, M. (2003). Evidence for a lack of DNA double-strand break repair in human cells exposed to very low x-ray doses. Proc. Natl. Acad. Sci. USA, 100 (9), 5057-5062.

Rupnik, A., Lowndes, N.F. \& Grenon, M. (2010). MRN and the race to the break. Chromosoma, 119 (2), 115-135.

Sage, E. \& Harrison, L. (2011). Clustered DNA lesion repair in eukaryotes: Relevance to mutagenesis and cell survival. Mutat. Res., 711 (1-2), 123-133.

San Filippo, J., Sung, P. \& Klein, H. (2008). Mechanism of eukaryotic homologous recombination. Annu. Rev. Biochem., 77, 229-257.

Sartori, A.A., Lukas, C., Coates, J., Mistrik, M., Fu, S., Bartek, J., Baer, R., Lukas, J. \& Jackson, S.P. (2007). Human CtIP promotes DNA end resection. Nature, 450 (7169), 509-514.

Sczepanski, J., Jacobs, A.C., Van Houten, B. \& Greenberg M. (2009). Double-strand break formation during nucleotide excision repair of a DNA interstrand cross-link. Biochemistry, 48 (32), 7565-7567.

Sedelnikova, O.A., Horikawa, I., Redon, C., Nakamura, A., Zimonjic, D., Popescu, N. \& Bonner, W.M. (2008). Delayed kinetics of DNA double-strand break processing in normal and pathological aging. Aging Cell, 7 (1), 89-100.

Semenenko, V.A. \& Stewart, R.D. (2004). A fast Monte Carlo algorithm to simulate the spectrum of DNA damages formed by ionizing radiation. Radiat. Res., 161 (4), 451-457.

Shibata, A., Barton, O., Noon, A.T., Dahm, K., Deckbar, D., Goodarzi, A.A., Lőbrich, M. \& Jeggo, P.A. (2010). Role of ATM and the damage response mediator proteins 53BP1 and MDC1 in the maintenance of G(2)/M checkpoint arrest. Mol. Cell Biol., 30 (13), 3371-3383.

Shikazono, N., Noguchi, M., Fujii, K., Urushibara, A. \& Yokoya, A. (2009). The yield, processing, and biological consequences of clustered DNA damage induced by ionizing radiation. J. Radiat. Res., 50 (1), 27-36.

Smits, V.A., Warmerdam, D.O., Martin, Y. \& Freire, R. (2010). Mechanisms of ATR-mediated checkpoint signalling. Front Biosci., 15, 840-853.

Smogorzewska, A., Desetty, R., Saito, T.T., Schlabach, M., Lach, F.P., Sowa, M. E., Clark, A.B., Kunkel T.A., Harper J.W., 
Colaiacovo M. \& Elledge, S.J. (2010). A genetic screen identifies FAN1, a Fanconi anemiaassociated nuclease necessary for DNA interstrand crosslink repair. Mol. Cell, 39 (1), 36-47.

Stewart, G.S., Wang, B., Bignell, C., Taylor, A.M. \& Elledge, S.J. (2003). MDC1 is a mediator of the mammalian DNA damage checkpoint. Nature, 421 (6926), 961-966.

Stracker, T.H., Usui, T. \& Petrini, J.H. (2009). Taking the time to make important decisions: the checkpoint effector kinases Chk1 and Chk2 and the DNA damage response. DNA Repair (Amst), 8 (9), 1047-1054.

Sutherland, B.M., Bennett, P.V., Sidorkina, O., \& Laval, J. (2000). Clustered DNA damages induced in isolated DNA and in human cells by low doses of ionizing radiation. Proc. Natl. Acad. Sci. USA, 97 (1), 103-108.

Sutherland, B.M., Bennett, P.V., Sutherland, J.C. \& Laval, J. (2002). Clustered DNA damages induced by $x$ rays in human cells. Radiat. Res., 157 (6), 611-616.

Svetlova, M.P., Solovjeva, L.V. \& Tomilin, N.V. (2010). Mechanism of elimination of phosphorylated histone from chromatin after repair of DNA double-strand breaks. Mutat. Res., 685 (1-2), 54-60.

Takahashi, A., Mori, E. \& Ohnishi T. (2010). The foci of DNA double strand breakrecognition proteins localize with $\gamma \mathrm{H} 2 \mathrm{AX}$ after heat treatment. J. Radiat. Res., 51 (1), 91-95.

Taki, K., Wang, B., Nakajima, T., Wu, J., Ono, T., Uenara, Y., Matsumoto, T., Oghiso, Y., Tanaka, K., Ichinohe, K., Nakamura, S., Tanaka, S., Magae, J., Kakimoto, A. \& Nenoi, M. (2009). Microarray analysis of differentially expressed genes in the kidneys and testes of mice after long-term irradiation with low-dose-rate $\gamma$-rays. $J$. Radiat. Res., 50 (3), 241-252

Tang, J., \& Greenberg, R.A. (2010). Connecting the dots: Interplay between ubiquitylation and sumoylation at DNA double strand breaks. Gen. Cancer, 1 (7), 787-796.

Terato, H. \& Ide, H. (2004). Clustered DNA damage induced heavy ion particles. Biol. Sci. Space, 18 (4), 206-212.

Thompson, L.H. \& Hinz, J.M. (2009). Cellular and molecular consequences of defective Fanconi anemia proteins in replication-coupled DNA repair: mechanistic insights. Mutat. Res., 668 (1-2), 54-72.

Tomita, M., Morohoshi, F., Matsumoto, Y., Otsuka, K. \& Sakai, K. (2008). Role DNA doublestrand breaks repair genes in cell proliferation under low-dose rate irradiation condition. J. Radiat. Res., 49 (5), 557-564.

Tsai, C.J., Kim, S.A. \& Chu, G. (2007). Cernunnos/XLF promotes the ligation of mismatched and non cohesive DNA ends. Proc. Natl. Acad. Sci. USA, 104 (19), 7851-7856.

Tubiana M ., Aurengo, A., Averbeck, D., \& Masse, R. (2006). The debate on the use of linear no threshold for assessing the effects of low doses. J. Radiol. Prot., 26 (3), 317-324.

Ulsh, B.A. (2010). Checking the foundation: recent radiobiology and the linear no-threshold theory. Health Phys., 99 (6), 747-758.

Vasquez, K.M. (2010). Targeting and processing of site-specific DNA interstrand crosslinks. Environ. Mol. Mutagen., 51 (6), 527-539.

Wang, B. \& Elledge, S.J. (2007). Ubc13/Rnf8 ubiquitin ligases control foci formation of the Rap80/Abraxas/Brca1/Brcc36 complex in response to DNA damage. Proc. Natl. Acad. Sci. USA, 104 (52), 20759-20763. 
Ward, J.F. (1988) DNA damage produced by ionizing radiation in mammalian cells: identities, mechanisms of formation, and reparability. Prog. Nucleic Acid Res. Mol. Biol., 35, 95-125.

Warmerdam, D.O. \& Kanaar, R. (2010). Dealing with DNA damage: Relationships between checkpoint and repair pathways. Mutat. Res., 704 (1-3), 2-11.

Warmerdam, D.O., Kanaar, R. \&. Smits, V.J. (2010). Differential Dynamics of ATR-Mediated Checkpoint Regulators. J. Nucleic Acids, aug. 17, Pii: 319142, doi: 10.4061/2010/319142

Wood, R.D. (2010). Mammalian nucleotide excision repair proteins and interstrand crosslink repair. Environ. Mol.Mutagen., 51 (6), 520-526.

Wu, Q. \& Vasquez, K.M. (2008). Human MLH1 protein participates in genomic damage checkpoint signaling in response to DNA interstrand crosslinks, while MSH2 functions in DNA repair. PLoS Genet. 4 (9), e1000189.

Wykes, S., Piasentin, E., Joiner, M.C., Wilson, G.D. \& Marples, B. (2006). Low-dose hyperradiosensitivity is not caused by a failure to recognize DNA double-strand breaks. Radiat. Res., 165 (5), 516-524.

$\mathrm{Xu}, \mathrm{Y} ., \quad \&$ Price, B.D. (2011). Chromatin dynamics and the repair of DNA double strand breaks. Cell Cycle, 10 (2), 261-267. Xue, L., Yu, D., Furusawa, Y., Cao, J., Okayasu, R. \& Fan, S. (2009). ATM-dependent hyper-radiosensitivity inmammalian cells irradiated by heavy ions. Int. J. Radiat. Oncol. Biol. Phys., 75 (1), 235-243.

Yamauchi, M., Oka, Y., Yamamoto, M., Niimura, K., Uchida, M., Kodama, S., Watanabe, M., Sekine, I., Yamashita, S. \& Suzuki, K. (2008). Growth of persistent foci of DNA damage checkpoint factors is essential for amplification of G1 checkpoint signaling. DNA Repair (Amst.), 7 (3), 405-417.

Yannone, S.M., Khan, I.S., Zhou, R.Z., Zhou, T., Valerie, K. \& Povirk, L.F. (2008). Coordinate $5^{\prime}$ and $3^{\prime}$ endonucleolytic trimming of terminally blocked blunt DNA double-strand break ends by Artemis nuclease and DNA-dependent protein kinase. Nucleic Acids Res., 36 (10), 3354-3365.

Yano, K., Moratomi-Yano, K., Adachi, N. \& Aiyama, H. (2009). Molecular mechanism of protein assembly on DNA double-strand breaks in the non-homologous endjoining pathway. J. Radiat. Res., 50 (1), 97-108

You, Z. \& Bailis, J.M. (2010). DNA damage and decisions: CtIP coordinates DNA repair and cell cycle checkpoints.Trends Cell Biol., 20 (7), 402-409.

Zou, L. \& Elledge, S.J. (2003). Sensing DNA damage through ATRIP recognition of RPAssDNA complexes. Science, 300 (5625), 1542-1548. 


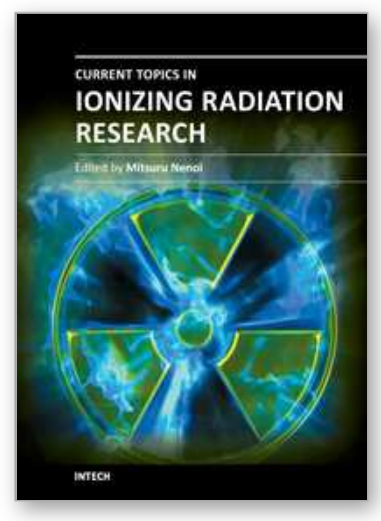

\author{
Current Topics in lonizing Radiation Research \\ Edited by Dr. Mitsuru Nenoi
}

ISBN 978-953-51-0196-3

Hard cover, 840 pages

Publisher InTech

Published online 12, February, 2012

Published in print edition February, 2012

Since the discovery of $X$ rays by Roentgen in 1895 , the ionizing radiation has been extensively utilized in a variety of medical and industrial applications. However people have shortly recognized its harmful aspects through inadvertent uses. Subsequently people experienced nuclear power plant accidents in Chernobyl and Fukushima, which taught us that the risk of ionizing radiation is closely and seriously involved in the modern society. In this circumstance, it becomes increasingly important that more scientists, engineers and students get familiar with ionizing radiation research regardless of the research field they are working. Based on this idea, the book "Current Topics in lonizing Radiation Research" was designed to overview the recent achievements in ionizing radiation research including biological effects, medical uses and principles of radiation measurement.

\title{
How to reference
}

In order to correctly reference this scholarly work, feel free to copy and paste the following:

Azhub Gaziev and Gadzhi Shaikhaev (2012). Limited Repair of Critical DNA Damage in Cells Exposed to Low Dose Radiation, Current Topics in lonizing Radiation Research, Dr. Mitsuru Nenoi (Ed.), ISBN: 978-953-510196-3, InTech, Available from: http://www.intechopen.com/books/current-topics-in-ionizing-radiationresearch/limited-repair-of-critical-dna-damage-in-cells-exposed-by-low-doses-of-radiation-

\section{INTECH}

open science | open minds

\author{
InTech Europe \\ University Campus STeP Ri \\ Slavka Krautzeka 83/A \\ 51000 Rijeka, Croatia \\ Phone: +385 (51) 770447 \\ Fax: +385 (51) 686166 \\ www.intechopen.com
}

\author{
InTech China \\ Unit 405, Office Block, Hotel Equatorial Shanghai \\ No.65, Yan An Road (West), Shanghai, 200040, China \\ 中国上海市延安西路65号上海国际贵都大饭店办公楼 405 单元 \\ Phone: +86-21-62489820 \\ Fax: $+86-21-62489821$
}


(C) 2012 The Author(s). Licensee IntechOpen. This is an open access article distributed under the terms of the Creative Commons Attribution 3.0 License, which permits unrestricted use, distribution, and reproduction in any medium, provided the original work is properly cited. 